\title{
On the inverse design of discontinuous abrasive surface to lower friction-induced temperature in grinding: An example of engineered abrasive tools
}

Hao Nan Lia,b, Dragos Axinteb,c,*

a School of Aerospace, The University of Nottingham Ningbo China, Ningbo 315100, PR China

b Department of Mechanical, Materials and Manufacturing Engineering, The University of Nottingham,

Nottingham, NG7 2RD, UK

Department of Mechanical, Materials and Manufacturing Engineering, The University of Nottingham Ningbo

China, Ningbo 315100, PR China

\begin{abstract}
In order to lower temperature, abrasive tools with passive-grinding, e.g. textured, areas (PGA) have been suggested. However, most of the reported PGA geometries (e.g. slots, holes) have been determined based on the engineering intuition (i.e. trial and error) rather than in-depth phenomenological analysis. To fill this gap, this paper proposes a method to design the PGA geometry according to the desired temperature, i.e. the inverse design method. In the method, the analytical model of grinding temperature for tools with PGA is established and treated as the primary constraint in the inverse problem, while the models of the ground surface roughness and grinding continuity as the subsidiary constraints. The method accuracy is validated by conducting grinding trials with tools with the calculated PGA geometries and comparing their performances (temperature, roughness and force fluctuation) to the required ones. In comparison with conventional tools, our tools designed by the method have been found effective to reduce harmful, or even destructive, thermal effects on the ground surfaces. This work might lay foundation for designing discontinuous abrasive tools, and future work can be probably extended to the tools or the workpiece with more complex shapes (e.g. ball end/cup tools, and free-form workpiece).
\end{abstract}

Keywords: engineered abrasive; grinding temperature; inverse design;

\section{Introduction}

It is well-known that one third of the world energy resources is now spent on overcoming friction in various physical, chemical and biological processes, and nearly all the energy dissipated in friction is converted into heat [1]. In most cases, the excessive friction-generated heat needs to be minimised, or at least kept under control, as it could lead to the degradation 
of contact surfaces, which can be manifested as changes in both mechanical and microstructural properties.

The need to lower friction-induced temperature also occurs in material removal processes, especially for those that rely on abrasive phenomena such as grinding. Unlike the processes where the material is sheared by the tools with defined sharp cutting edges (e.g. drilling, milling), in grinding the material is removed by the attritive interaction between the abrasive

\section{Nomenclature}

\begin{tabular}{|c|c|c|c|}
\hline$a_{p}$ & grinding depth $(\mathrm{mm})$ & $R z_{\text {required }}$ & required surface roughness $(\mu \mathrm{m})$ \\
\hline$\vec{b}$ & tool-workpiece contact width (mm) & $T$ & measured grinding temperature $\left({ }^{\circ} \mathrm{C}\right)$ \\
\hline$C$ & grain number per area $(/ \mathrm{mm})$ & $\Delta T$ & grinding temperature reduction $\left({ }^{\circ} \mathrm{C}\right)$ \\
\hline$c$ & specific heat capability of workpiece $(\mathrm{J} / \mathrm{kg} \cdot \mathrm{K})$ & $T_{b}$ & coolant boiling point $\left({ }^{\circ} \mathrm{C}\right)$ \\
\hline$c_{c}$ & specific heat capability of coolant $(\mathrm{J} / \mathrm{kg} \cdot \mathrm{K})$ & $T_{c 0}$ & $\begin{array}{l}\text { initial coolant temperature before it enters the } \\
\text { grinding zone }\left({ }^{\circ} \mathrm{C}\right)\end{array}$ \\
\hline$d_{\max , \min }$ & $\begin{array}{l}\text { maximum and minimum grain diameters } \\
(\mathrm{mm})\end{array}$ & $T_{e}$ & system equilibrium temperature $\left({ }^{\circ} \mathrm{C}\right)$ \\
\hline$d_{s}$ & abrasive tool diameter $(\mathrm{mm})$ & $T_{m}$ & $\begin{array}{l}\text { full temperature field induced by multiple } \\
\text { grains }\left({ }^{\circ} \mathrm{C}\right)\end{array}$ \\
\hline$d t$ & differential timestep (s) & $T_{\text {required }}$ & required grinding temperature $\left({ }^{\circ} \mathrm{C}\right)$ \\
\hline$E_{b}$ & $\begin{array}{l}\text { thermal energy that is taken away from the } \\
\text { material to increase the transported coolant } \\
\text { temperature until boiling }(\mathrm{J})\end{array}$ & $T_{s}(x, y, z, t)$ & nonsteady-state 3D temperature field $\left({ }^{\circ} \mathrm{C}\right)$ \\
\hline$E_{e}$ & $\begin{array}{l}\text { thermal energy that is taken away from the } \\
\text { material to continuously evaporate the } \\
\text { boiling coolant }(\mathrm{J})\end{array}$ & $t$ & time $(\mu s)$ \\
\hline$E_{t}$ & $\begin{array}{l}\text { total thermal energy that is taken away by } \\
\text { coolant }(\mathrm{J})\end{array}$ & $t^{\prime}$ & the moment when heat source acts $(\mu s)$ \\
\hline$F_{a}$ & axial grinding force $(\mathrm{N})$ & $t_{b}$ & time duration to boil the coolant $(\mu \mathrm{s})$ \\
\hline$F_{a-l e f t}$ & $\begin{array}{l}\text { axial forces induced by the left PGA part (see } \\
\text { Fig.10a) (N) }\end{array}$ & $t_{c}$ & $\begin{array}{l}\text { time duration from the coolant enters to } \\
\text { escapes the grinding zone }(\mu \mathrm{s})\end{array}$ \\
\hline$F_{a-r i g h t}$ & $\begin{array}{l}\text { axial forces induced by the right PGA part } \\
\text { (see Fig.10a) }(\mathrm{N})\end{array}$ & $t_{e}$ & $\begin{array}{l}\text { time duration for the system to achieve } \\
\text { thermal equilibrium }(\mu \mathrm{s})\end{array}$ \\
\hline$H_{p g a}$ & PGA depth (mm) & $v_{\text {grain }}$ & grain velocity $(\mathrm{m} / \mathrm{s})$ \\
\hline$h$ & $\begin{array}{l}\text { heat transfer coefficient of workpiece } \\
(\mathrm{W} / \mathrm{m} \cdot \mathrm{K})\end{array}$ & $v_{w}$ & material feed speed $(\mathrm{m} / \mathrm{s})$ \\
\hline$h_{\max , \min }$ & largest and smallest grain protrusions (mm) & $v_{x, y, z}$ & translational speed $(\mathrm{m} / \mathrm{s})$ \\
\hline$k$ & workpiece thermal conductivity $(\mathrm{W} / \mathrm{m} \cdot \mathrm{K})$ & $w_{a}$ & active-grinding region width $(\mathrm{mm})$ \\
\hline$L_{1,2,3,4,5,6,7}$ & $\begin{array}{l}\text { tool-workpiece contact width (see Fig.2) } \\
(\mathrm{mm})\end{array}$ & $w_{p}$ & passive-grinding region width (mm) \\
\hline$l$ & one pass length (see Section 4) (mm) & $x, y_{1,2}$ & $\begin{array}{l}x \text { and } y \text { coordinate of grain } 1 \text { and } 2 \text { (see Fig.2) } \\
(\mathrm{mm})\end{array}$ \\
\hline$l_{g}$ & tool-workpiece contact length (mm) & $y_{1,2 \max , 1,2 \min }$ & $\begin{array}{l}\text { maximum and minimum y coordinate of grain } \\
1 \text { and } 2(\mathrm{~mm})\end{array}$ \\
\hline$M$ & abrasive size number (\#) & $y_{q}$ & $\begin{array}{l}\text { y coordinate of the intersection point } Q \text { in } \\
\text { reference to the coordinate } \mathrm{x}_{1} \mathrm{O}_{1} \mathrm{y}_{1} \text { (see Fig. } 4 \text { ) } \\
(\mathrm{mm})\end{array}$ \\
\hline$m_{m}$ & workpiece mass $(\mathrm{kg})$ & $\rho$ & workpiece density $\left(\mathrm{kg} / \mathrm{m}^{3}\right)$ \\
\hline$n$ & positive integer & $\rho_{c}$ & coolant density $\left(\mathrm{kg} / \mathrm{m}^{3}\right)$ \\
\hline$n g$ & $\begin{array}{l}\text { total number of grains that are contacting } \\
\text { with the workpiece in the grinding zone }\end{array}$ & $\alpha$ & thermal diffusivity of workpiece $\left(\mathrm{E}^{-6} \cdot \mathrm{m}^{2} \cdot \mathrm{s}^{-1}\right)$ \\
\hline$n_{\text {grain }}$ & $\begin{array}{l}\text { grain number within the active-grinding } \\
\text { region }\end{array}$ & $\beta$ & angle relative to the tool axial direction $\left(^{\circ}\right)$ \\
\hline$Q$ & heat quantity of heat source & $\mu$ & mean distribution of grain size $(\mathrm{mm})$ \\
\hline$q$ & heat flux density $(\mathrm{J} / \mathrm{s})$ & $\sigma$ & standard deviation of grain size (mm) \\
\hline$R_{z}$ & measured surface roughness $(\mu \mathrm{m})$ & $\chi$ & coolant evaporation heat $(\mathrm{J} / \mathrm{kg})$ \\
\hline
\end{tabular}

edges of undefined geometries and the workpiece material. This leads to a high value of specific energy (energy to remove a unit volume of workpiece material) associated with 
elevated temperature at tool-workpiece contact area (even more than $1200{ }^{\circ} \mathrm{C}$ in certain cases [2]) when compared with machining with defined cutting edges.

Although the morphology of the abrasive tool surfaces are discontinuous at microscale (grains, binder and porosities discretely and randomly distributed), the limited micro gaps between neighboring grains are found insufficient to provide enough grain-materialdisengagement period and coolant reservoir space to cool down the tool-workpiece material contact zone [2]. High temperature and the corresponding workpiece thermal damage (manifested as heat affected zones) caused by intensive cutting parameters therefore, is treated as one of the toughest issues in abrasive processes [3].

As seen in Fig.1 (a), one potential solution to reduce thermal damage on the workpiece is to alter the tool-workpiece contact from continuous to discontinuous/intermittent nature by artificially creating special regions without abrasive grains, or Passive-Grinding Area (PGA), on the tool surfaces. In this context, these "engineered" abrasive tools can be categorised into [4]: (i) segmented tools, where the PGA was created by assembling individual abrasive segments onto a tool hub with specific gaps; and (ii) textured tools, where the PGA was achieved by removing abrasive grain area from conventional tool surfaces.

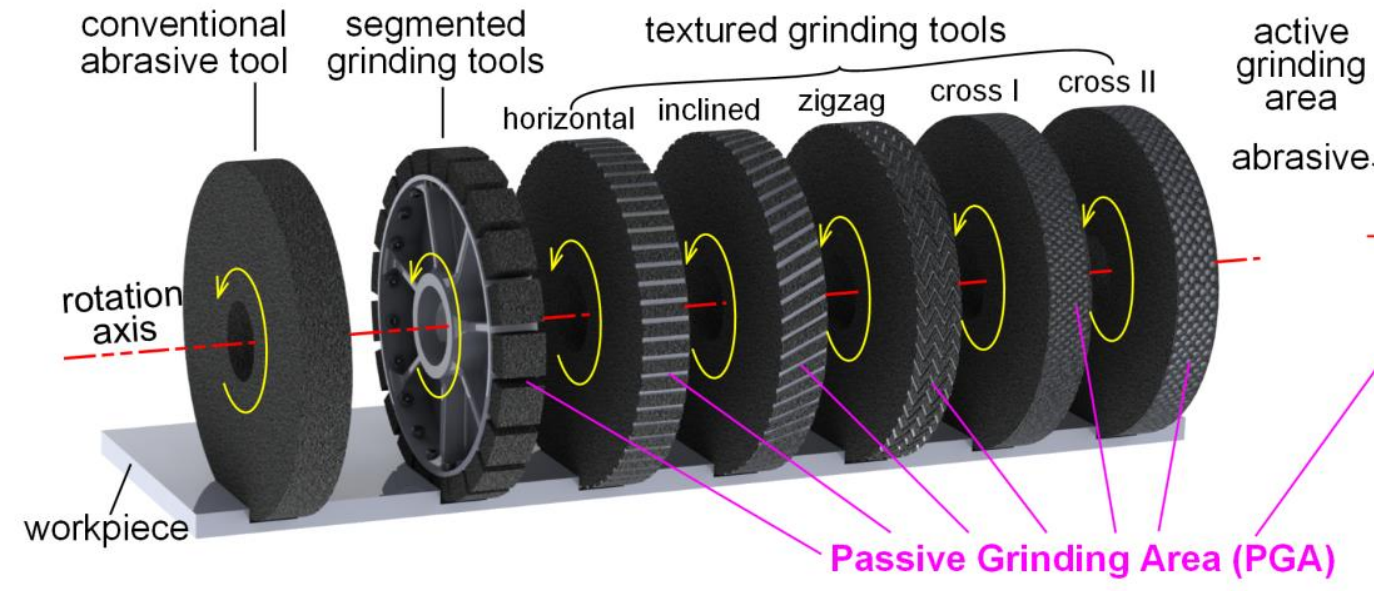

(a)

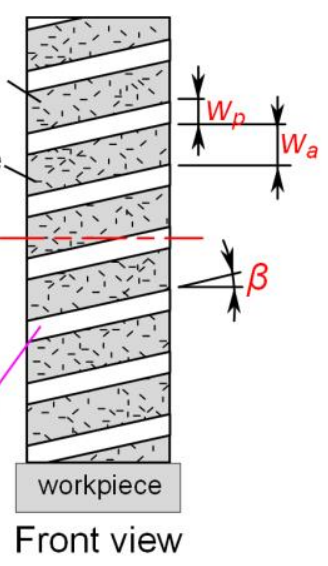

(b)

Figure 1. (a) Illustration of abrasive tools with the Passive Grinding Area (PGA) including both segmented and textured grinding tools, (b) The simplified linear GPA geometries defined by $w_{p}, \beta$, and $w_{a}$

By employing abrasive tools with discontinuous surfaces, significant temperature reduction of $105^{\circ} \mathrm{C}$ for aluminum [5], $195^{\circ} \mathrm{C}$ for steel [6], and $20{ }^{\circ} \mathrm{C}$ for $\mathrm{GH} 4169$ [6] and TC4 alloy [7] was observed in grinding experiments in comparison with conventional tools with continuous peripheral abrasive surface.

Despite the reported research on the use of abrasive tools with discontinuous surface, very few efforts have been noted to theoretically model the temperature reduction for a known PGA geometry under certain conditions. This is the direct problem to solve: given the geometrical characteristics of a specific PGA, determine the reduction in cutting temperature at the tool-material interfaces. Therefore, the tool performances can be neither predicted nor 
optimised until iterative experimental trials are performed with tools having various PGA geometries.

What is more imperative here is to propose a design method which can determine the PGA geometry according to the desired grinding temperature, i.e. the inverse problem. In fact, similar inverse problems in various kinds of time-dependent processes have been extensively studied, including abrasive waterjet, laser and ion beam machining [8]. However, most previous studies have been focused on the process kinematics (e.g. feed rates, tool paths) to generate the freeform surfaces. To the best knowledge of the authors, no inverse design was presented for designing tool geometry, let alone in the process relying on randomly undefined cutting edges such as grinding.

The aim of the paper is to propose a generalised inverse method to design discontinuities, or PGA, on the abrasive tool surface according to the desired grinding temperature. In the article, firstly, the direct problem has been solved by analytically establishing the relationship between the PGA geometry and the temperature at the tool-workpiece interface. Then, the ground surface roughness and grinding continuity have also been modelled for the tool with PGA to provide constraints to the feasible domain of the multivariate inverse problem. Finally, the inverse problem has been mathematically solved by using a simple yet effective numerical quadrature, the closed Newton-Cotes formulae.

\section{Problem formulation}

\subsection{Simplification of the GPA geometry}

Although PGA shapes/patterns reported in the literature [4] are diverse (see horizontal, inclined, zigzag, and cross patterns in Fig.1a), the simple linear geometry of PGA (that can also be economically generated) could be generally charaterised by three elements (see Fig.1b): (1) PGA width $w_{p}$; (2) angle relative to the tool axial direction $\beta$; and (3) activegrinding region width $w_{a}$. To provide a generic inverse design method, the simple PGA geometry in Fig.1 (b) therefore is firstly used in the following theoretical modelling (see Section 3), after which the solved geometry is optimised to overcome some practical issues, e.g. the undesired load distribution induced by the tool-workpiece interaction (see Section 5.2). Please note that here the PGA depth has not been taken into account as varied region depths were found to provide similar cooling performances $[9,10]$.

\subsection{Constraints in the inverse problem}

In order to inversely solve the three PGA parameters $\left(w_{p}, \beta\right.$ and $\left.w_{a}\right)$, three independent algebraic equations, or at least three independent inequalities, should be provided according to the optimal solution theory of the nonlinear multivariate problem [11]. 
Here the desired grinding temperature $T_{\text {required }}$ is considered as the primary condition because the key advance of tools with PGA is to lower grinding temperature and reduce thermal effects on material surfaces including microstructural changes and mechanical property alterations.

Although tools with PGA was reported to be effective to lower temperature [4], the ground surface roughness was experimentally found larger in comparison with conventional tools $[4$, 12-14]. Hence, the ground surface roughness $R z_{\text {required }}$ is treated as the subsidiary constraint as grinding is usually employed as the last finishing operation and therefore the machined surface quality should still be in demand [4, 12-14].

Due to the geometrical periodicity of PGA, the intermittent tool-material engagement and disengagement would occur during grinding process, resulting in the forced vibration of the tool-workpiece-machine system [4]. Thus, the grinding continuity, which can be quantified by the grinding force fluctuation, should be required to be lower than an acceptable threshold level.

One note here is that, except for the PGA geometry parameters, there are many other parameters influencing the grinding process in terms of the above constraints. Therefore, in order to consider all these factors, the mechanical, geometrical, thermal, and physical parameters of the abrasive tool, the workpiece, the coolant and the grinding process will be introduced in the proposed method (see both Section 3 and Nomenclature table).

Please note that, all the above factors might not evenly influence the grinding temperature, ground surface roughness, and grinding chatter, and this uneven effects will be inherently considered in the proposed method because the method will be analytically derived from the basic geometrics, physics, and thermodynamics theories where all the above parameters will be used.

Besides, in the following parts, the effects of the PGA geometry parameters $\left(w_{p}, \beta\right.$ and $\left.w_{a}\right)$ on the above constraints are discussed in details. This is not because the PGA parameters are the only influencing factors on grinding performances, but is because the main focus of this paper is to propose a theoretical inverse design method to improve the previous experimental trial-and-error approaches during the PGA geometry design.

The following comparison between the theoretical and experimental results (see Section 5.1) will also prove the method feasibility and accuracy in the grinding trials where different grinding temperature, ground surface roughness, and grinding chatter are required under different grinding conditions.

\section{The inverse design method}

The inverse design method is based on analytical solution of the direction problem, i.e. the mathematical relationships between the PGA geometry and grinding temperature, ground 
surface roughness, and grinding continuity. Based on the above three conditions, the inverse problem can be mathematically solved by using a simple yet effective numerical quadrature, the closed Newton-Cotes formulae.

\subsection{Primary constraint - Grinding temperature for tools with PGA}

Previous grinding temperature models assumed the heat flux within the tool-workpiece contact zone as uniform along the contact width [3]. However, this assumption obviously cannot apply for the tools with PGA as these engineered abrasive tools lead to continuous change of the tool-workpiece contact width (see different widths in cross section 1 to 3 in Fig.2a), and therefore, the non-uniform heat flux occurs along the width direction. 


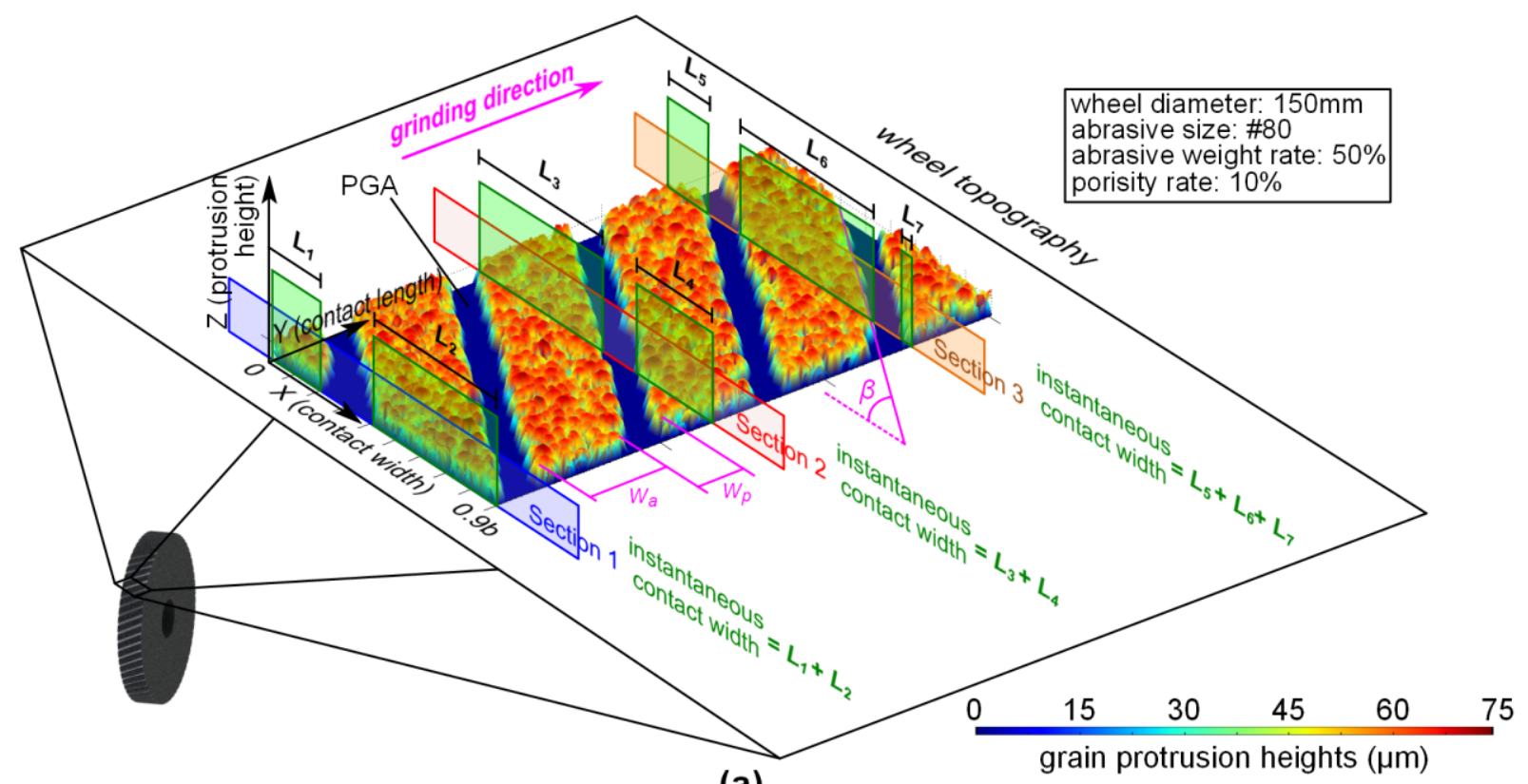

(a)

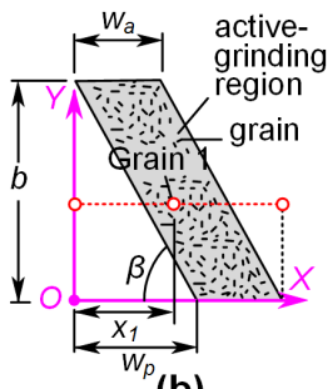

(b)

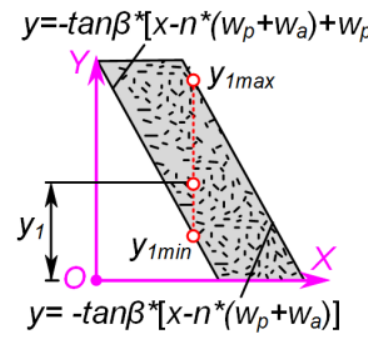

(c)

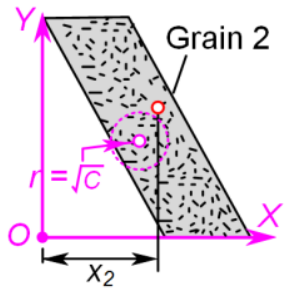

(d)

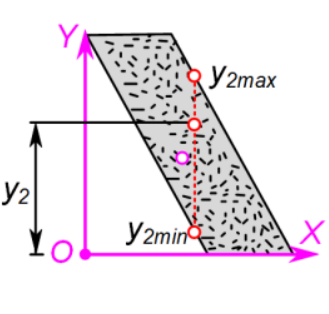

(e)

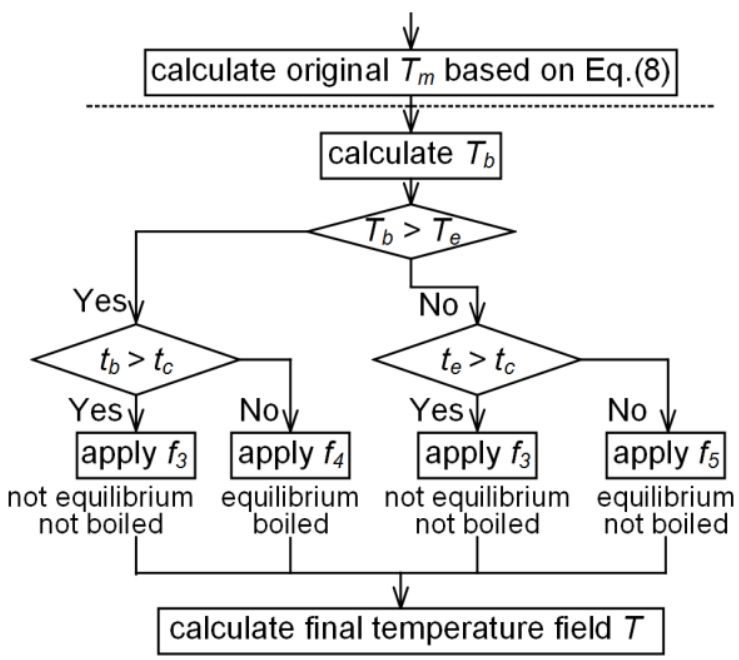

(f)

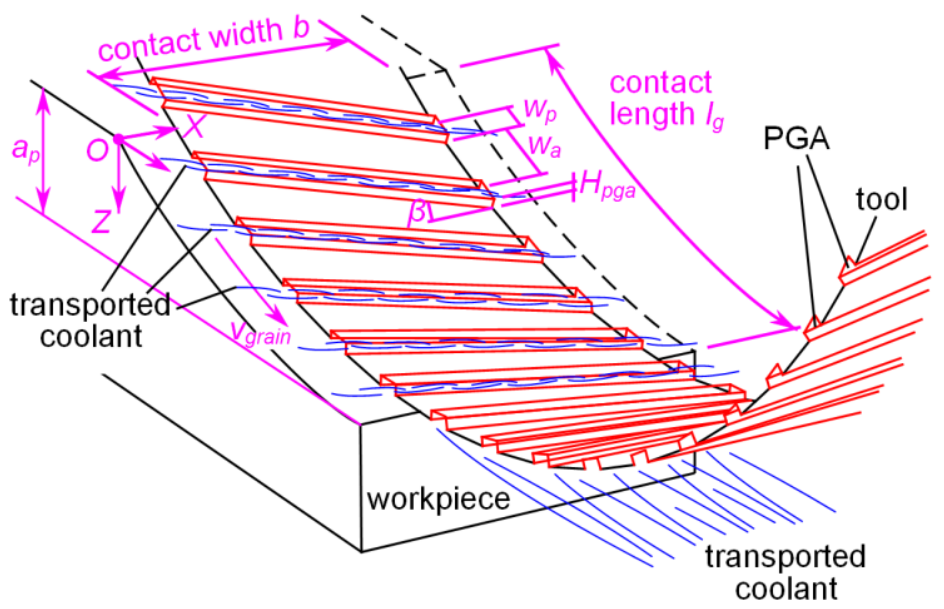

(g)

Figure 2. Grinding temperature modelling for tools with PGA. (a) Illustration of the changing instantaneous toolmaterial contact width (see the contact widths separately in the sections 1, 2, 3 as examples), (b-e) abrasive tool topography modelling procedures where the grains with normal-distributed grain sizes are randomly located on the active grinding region, (f) calculation flowchart of the tool-workpiece contact zone temperature taking into consideration the thermal equilibrium of both coolant-workpiece system and coolant boiling status, and $(\mathrm{g})$ illustration on how the coolant is transported into the tool-workpiece contact zone by the PGA geometry

In order to address this, we have proposed a grinding temperature modelling method for tools with PGA, in which the temperature field induced by each individual cutting grain was firstly 
calculated and then summed together so that the effects of the missing grains within PGA on temperature can be inherently considered in the calculation. With this, the explicit link between the PGA geometry and the workpiece temperature developed by the multitude of single grits can be mathematically built.

The present methodology originates from our preliminary study [3], however, two important improvements have been performed in this article: (i) modelling the grain-stochastic tool topography considering PGA, and (ii) calculating grain-discretised grinding temperature field considering the cooling performances of the coolant that are transported into the toolworkpiece contact zone by PGA.

\subsubsection{Modelling of the grain-stochastic tool topography considering PGA}

The mathematical description of the tool topography is the foundation of this problem because it is the grains on the topography that do the grinding. The topography of the tool with PGA is random because grains have various shapes and sizes stochastically distributed on the tool periphery surface. More importantly, only the grains located within the active grinding region should be modelled so as to manifest the tool surface discontinuity.

The topography modelling is conducted by separately defining each grain location, shape and size. For the location, as seen in Fig.2 (b), the $x$ coordinate of grain 1 (denoted as $x_{1}$ ) is firstly randomly selected within the interval $\left[n *\left(w_{a}+w_{p}\right)-w_{p}, n *\left(w_{a}+w_{p}\right)\right](n$ is a positive integer). Then, as seen in Fig.2 (c), in order to define grain 1 in the active grinding region, its $y$ coordinate $y_{1}$ should be a random value within the interval $\left[y_{1 \min }, y_{1 \max }\right]$ where $y_{1 \min }=-\tan \beta *\left[x_{1}-n *\left(w_{a}+w_{p}\right)+w_{p}\right]$ and $y_{1 \max }=-\tan \beta *\left[x_{1}-n *\left(w_{a}+\right.\right.$ $\left.w_{p}\right)$ ], because the active region can be defined by

$$
-\tan \beta *\left[x-n *\left(w_{a}+w_{p}\right)+w_{p}\right]<y<-\tan \beta *\left[x-n *\left(w_{a}+w_{p}\right)\right] .
$$

Then, as seen in Fig.2 (d), based on the grain number per unit volume (grain volume density), the $x$ coordinate of grain 2 (denoted as $x_{2}$ ) can also be randomly selected outside of the circle having the center $\left(x_{1}, y_{1}\right)$ and radius $r=\sqrt{C}$, where the grain number per unit area (or grain area density) $C$ is equal to abrasive size number $M / 15.2$ [2]. Then, as seen in Fig.2 (e), the $y$ coordinate of grain 2 can be obtained by randomly selecting a value $y_{2}$ within the range $\left[y_{2 \min }, y_{2 \max }\right]$ where $y_{2 \min }=-\tan \beta *\left[x_{2}-n *\left(w_{a}+w_{p}\right)+w_{p}\right]$ and $y_{2 \max }=$ $-\tan \beta *\left[x_{2}-n *\left(w_{a}+w_{p}\right)\right]$. Similar steps are iteratively performed until the desired grain number within the active-grinding region $n_{\text {grain }}=b * w_{a} * C$ is reached where $b$ refers to the contact width. For the grain size and shape modeling, similar to [15, 16], the 
experimentally validated ellipsoid geometry with the normally-distributed long and short axis lengths are used. Fig.2 (a) gives a part of the modelled tool topography with PGA based on above steps, where each grain coordinate $\left(x_{i}, y_{i}\right)$ is simply expressed as Eq.(2) to clarify the following derivation.

$$
x_{i}=f_{1}\left(w_{a}, w_{p}, \beta\right), y_{i}=f_{2}\left(w_{a}, w_{p}, \beta\right) \text {, and } z_{i}=f_{3}\left(w_{a}, w_{p}, \beta\right)
$$

\subsubsection{Calculation of grain-discretised grinding temperature field considering the cooling performances of the coolant}

The basic principle of the temperature calculation is based on the moving point heat source theory [17], because the grain-workpiece contact area is small in relative to the whole toolworkpiece contact zone. Based on the theory, the nonsteady-state three-dimensional temperature field $T_{s}(x, y, z, t)$ induced by a moving point heat source with the translational speed of $\left(v_{x}, v_{y}, v_{z}\right)$ satisfies the following equations

$$
k \frac{\partial^{2} T_{s}}{\partial x^{2}}=\rho c\left(\frac{\partial T_{s}}{\partial t}-v_{x} * \frac{\partial T_{s}}{\partial x}\right), k \frac{\partial^{2} T_{s}}{\partial y^{2}}=\rho c\left(\frac{\partial T_{s}}{\partial t}-v_{y} * \frac{\partial T_{s}}{\partial y}\right), k \frac{\partial^{2} T_{s}}{\partial z^{2}}=\rho c\left(\frac{\partial T_{s}}{\partial t}-v_{z} * \frac{\partial T_{s}}{\partial z}\right)
$$

in which $k, \rho, c$ are separately the thermal conductivity, density and specific heat capability of the material, $(x, y, z)$ is a certain Cartesian point in the temperature field, $t$ is the time, and the initial conditions is

$$
\left.T_{s}(x, y, z, t)\right|_{t=0}=T_{s_{x \rightarrow \pm \infty}, y \rightarrow \pm \infty, z \rightarrow \pm \infty}=20^{\circ} \mathrm{C} \text { (room temperature). }
$$

Because Eq.(4) can be treated as the typical second-order homogenous partial differential equation, its full generic solution can be written as [18]

$$
\begin{aligned}
& T_{S}\left(x, y, z, t, x^{\prime}, y^{\prime}, z^{\prime}, t^{\prime}\right)=\frac{\alpha Q}{k}\left\{\frac{2}{\left[4 \pi \alpha\left(t-t^{\prime}\right)\right]^{3 / 2}} e^{-\frac{\left[\left(x-x^{\prime}\right)+v_{\text {grain }}\left(t-t^{\prime}\right)\right]^{2}+\left(y-y^{\prime}\right)^{2}+\left(z-z^{\prime}\right)^{2}}{4 \alpha\left(t-t^{\prime}\right)}}-\frac{h}{4 \pi \alpha k\left(t-t^{\prime}\right)} .\right. \\
&\left.\quad \operatorname{erfc}\left(\frac{z}{2 \sqrt{a\left(t-t^{\prime}\right)}}+\frac{h}{k} \sqrt{a\left(t-t^{\prime}\right)}\right) \cdot e^{z \cdot h / k+\alpha\left(t-t^{\prime}\right)(h / k)^{2}-\frac{\left[\left(x-x^{\prime}\right)^{2}+v_{\text {grain }}\left(t-t^{\prime}\right)\right]^{2}+\left(y-y^{\prime}\right)^{2}}{4 \alpha\left(t-t^{\prime}\right)}}\right\}
\end{aligned}
$$

where $\left(x^{\prime}=f_{1}\left(w_{a}, w_{p}, \beta\right), y^{\prime}=f_{2}\left(w_{a}, w_{p}, \beta\right), z^{\prime}=f_{3}\left(w_{a}, w_{p}, \beta\right)\right), Q$ and $t^{\prime}$ are separately the heat source Cartesian position and the heat quantity, and the time when the heat source acts, $v_{\text {grain }}$ is the grain velocity, and $h$ is the material heat transfer coefficient.

Therefore, the differential temperature field induced by a differential moving point heat source having the heat flux density of $q$ and acting in a differential timestep $d t$ can be written as 


$$
\begin{aligned}
d T_{s}\left(x, y, z, t, x^{\prime}, y^{\prime}, z^{\prime}, t^{\prime}\right)= & \frac{\alpha q}{k}\left\{\frac{2}{\left[4 \pi \alpha\left(t-t^{\prime}\right)\right]^{3 / 2}} e^{-\frac{\left[\left(x-x^{\prime}\right)+v_{\text {grain }}\left(t-t^{\prime}\right)\right]^{2}+\left(y-y^{\prime}\right)^{2}+\left(z-z^{\prime}\right)^{2}}{4 \alpha\left(t-t^{\prime}\right)}}\right. \\
& -\frac{h}{4 \pi \alpha k\left(t-t^{\prime}\right)} \operatorname{erfc}\left[\frac{z}{2 \sqrt{a\left(t-t^{\prime}\right)}}+\frac{h}{k} \sqrt{a\left(t-t^{\prime}\right)}\right] * e^{z \cdot h / k+\alpha\left(t-t^{\prime}\right)(h / k)^{2}} \\
& \left.* \exp \left\{-\frac{\left[\left(x-x^{\prime}\right)^{2}+v_{\text {grain }}\left(t-t^{\prime}\right)\right]^{2}+\left(y-y^{\prime}\right)^{2}}{4 \alpha\left(t-t^{\prime}\right)}\right\}\right\} d x^{\prime} d y^{\prime} d z^{\prime} d t^{\prime}
\end{aligned}
$$

Thus the full temperature field induced by a single heat source can be finally written as

$$
\begin{aligned}
T_{s}\left(x, y, z, t, x^{\prime}, y^{\prime}, z^{\prime}, t^{\prime}\right)= & \int_{0}^{b} \int_{0}^{l_{g}} \int_{0}^{a_{p}} \int_{0}^{t}\left\{\frac{2 \alpha q}{k\left[4 \pi \alpha\left(t-t^{\prime}\right)\right]^{3 / 2}} e^{-\frac{\left[\left(x-x^{\prime}\right)+v_{\text {grain }}\left(t-t^{\prime}\right)\right]^{2}+\left(y-y^{\prime}\right)^{2}+\left(z-z^{\prime}\right)^{2}}{4 \alpha\left(t-t^{\prime}\right)}}\right. \\
& -\frac{h}{4 \pi \alpha k\left(t-t^{\prime}\right)} \operatorname{erfc}\left[\frac{z}{2 \sqrt{a\left(t-t^{\prime}\right)}}+\frac{h}{k} \sqrt{a\left(t-t^{\prime}\right)}\right] * e^{z \cdot h / k+\alpha\left(t-t^{\prime}\right)(h / k)^{2}} \\
& \left.* \exp \left\{-\frac{\left[\left(x-x^{\prime}\right)^{2}+v_{\text {grain }}\left(t-t^{\prime}\right)\right]^{2}+\left(y-y^{\prime}\right)^{2}}{4 \alpha\left(t-t^{\prime}\right)}\right\}\right\} d x^{\prime} d y^{\prime} d z^{\prime} d t^{\prime} \text { (7) }
\end{aligned}
$$

where $l_{g}=\sqrt{d_{s} \cdot a_{p}}$ is the tool-workpiece contact length, $d_{s}$ is the abrasive tool diameter, and $a_{p}$ is the grinding depth. Considering $\operatorname{erf}\left[z / 2 \sqrt{a\left(t-t^{\prime}\right)}+h / k \sqrt{a\left(t-t^{\prime}\right)}\right]$ is minuteness, Eq.(7) can be simplified as

$$
T_{s}=\int_{0}^{b} \int_{0}^{l_{g}} \int_{0}^{a_{p}} \int_{0}^{t} \frac{2 \alpha q}{k\left[4 \pi \alpha\left(t-t^{\prime}\right)\right]^{3 / 2}} e^{-\frac{\left[\left(x-x^{\prime}\right)+v_{\text {grain }}\left(t-t^{\prime}\right)\right]^{2}+\left(y-y^{\prime}\right)^{2}+\left(z-z^{\prime}\right)^{2}}{4 \alpha\left(t-t^{\prime}\right)}} d x^{\prime} d y^{\prime} d z^{\prime} d t^{\prime}
$$

Thus, the full temperature field induced by multiple grains $T_{m}$ can be expressed as $T_{m}=f_{4}=$

$$
\sum_{i=1}^{n g} \int_{0}^{b} \int_{0}^{l_{g}} \int_{0}^{a_{p}} \int_{0}^{t} \frac{2 \alpha q}{k\left[4 \pi \alpha\left(t-t^{\prime}\right)\right]^{\frac{3}{2}}} e^{-\frac{\left[\left(x-x^{\prime}\right)+v_{\text {grain }}\left(t-t^{\prime}\right)\right]^{2}+\left(y-y^{\prime}\right)^{2}+\left(z-z^{\prime}\right)^{2}}{4 \alpha\left(t-t^{\prime}\right)}} d x^{\prime} d y^{\prime} d z^{\prime} d t^{\prime}
$$

where $n g$ is the total number of grains that are contacting with the workpiece in the grinding zone, and $(i)$ means the current calculation is performed for the grain $i$.

In order to describe the superior cooling performance of tools with PGA, the cooling effect of the cutting fluid transported by the PGA on the grinding temperature is calculated and introduced to the obtained $T_{m}$. Here, two important conditions dominate the calculation: (1) 
whether the coolant is under the boiling condition or not, and (2) whether the coolantworkpiece system reaches thermal equilibrium before the coolant leaves the grinding zone. As seen in Fig.2 (f) and (g), these two conditions can be determined by separately comparing (1) the system equilibrium temperature $T_{e}$ with the coolant boiling point $T_{b}$, and (2) the time duration for the system to achieve thermal equilibrium $t_{e}$, and the time duration to boil the coolant $t_{b}$, with the time duration from the coolant enters to escapes the grinding zone $t_{c}$. Based on the second law of thermodynamics [19] it could have

$$
\begin{gathered}
T_{e}=f_{5}=\frac{T_{m} \cdot m_{m} \cdot c+T_{c 0} \cdot \rho_{c} \cdot H_{p g a} \cdot b \cdot w_{p} \cdot l_{g} /\left(w_{a}+w_{p}\right) \cdot c_{c}}{m_{m} \cdot c+H_{p g a} \cdot b \cdot w_{p} \cdot l_{g} /\left(w_{a}+w_{p}\right) \cdot c_{c}} \\
t_{b}=f_{6}=\frac{\left[\left(T_{b}-T_{c 0}\right) \cdot \rho_{c} \cdot c_{c}+\gamma\right] \cdot H_{p g a} \cdot b \cdot w_{p} \cdot l_{g} /\left(w_{a}+w_{p}\right)}{\sum_{i=1}^{n g} q^{(i)}} \\
t_{e}=f_{7}=\frac{m_{m} \cdot c \cdot H_{p g a} \cdot\left(w_{a}+w_{p}\right)}{-k \cdot w_{p} \cdot b \cdot l_{g}} \\
t_{c}=l_{g} / v_{\text {grain }}
\end{gathered}
$$

where $m_{m}$ is the workpiece mass, $T_{c 0}$ is the initial coolant temperature before it enters the grinding zone, $\rho_{c}$ and $c_{c}$ are separately the density and the specific heat capability of the coolant, and $H_{p g a}$ is the PGA depth.

Based on above, the final temperature field considering the cooling effect is:

$\bigcirc$ when $T_{e}>T_{b}$ and $t_{b}>t_{c}$ (i.e. the coolant-material system does not achieve thermal equilibrium and the coolant is not boiled in grinding)

$$
T=f_{8}=T_{m}-\left(T_{m}-T_{e}\right) \cdot t_{c} / t_{e}
$$

$\bigcirc$ when $T_{e}>T_{b}$ and $t_{b} \leq t_{c}$ (i.e. the coolant-material system does not achieve thermal equilibrium while the coolant is boiled in grinding)

$$
T=f_{9}=T_{b}
$$

$\bigcirc$ when $T_{e} \leq T_{b}$ and $t_{b}>t_{c}$ (i.e. the coolant-material system does not achieve thermal equilibrium and the coolant is not boiled in grinding)

$$
T=f_{8}=T_{m}-\left(T_{m}-T_{e}\right) \cdot t_{c} / t_{e}
$$

$\bigcirc$ when $T_{e} \leq T_{b}$ and $t_{b} \leq t_{c}$ (i.e. the coolant-material system achieves thermal equilibrium while the coolant is not boiled in grinding)

$$
T=f_{10}=T_{e}
$$

Fig.3 shows a typical temperature domain of the tool-workpiece contact zone calculated by the above method. It can find that, as expected, the obtained temperature domain not only is 
non-uniform along the contact width (see the temperature in the cross sections $1,2,3$ ), but also contains the detailed thermal information (e.g. the temperature rise induced by the single cutting grain from its engagement to disengagement). More encouragingly, as anticipated, the low temperature region cooled by the transported coolant shows similar shape to the PGA geometry.

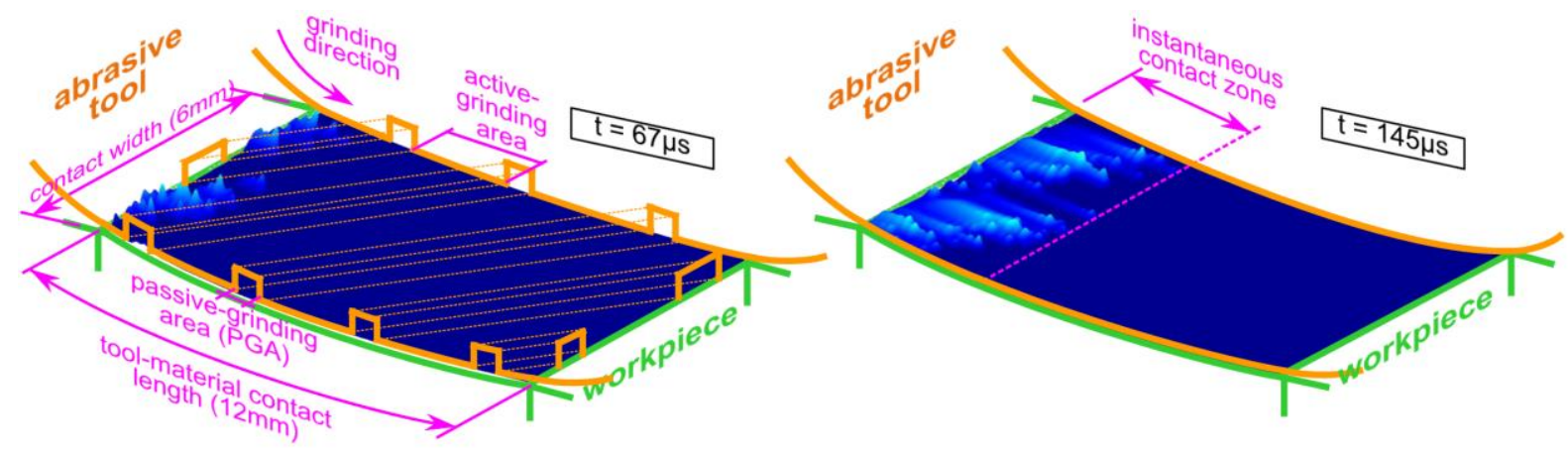

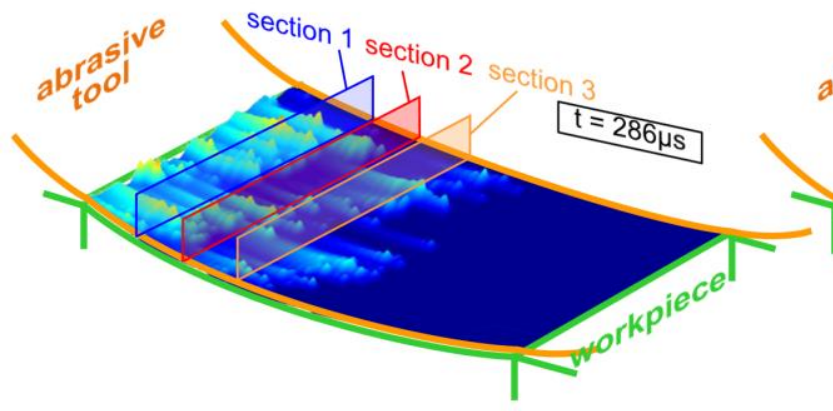

grain speed: $30 \mathrm{~m} / \mathrm{s}$ (tool rotation speed of $3820 \mathrm{rpm}$ ) workpiece feed speed: $1.2 \mathrm{~m} / \mathrm{min}$ depth of cut: $15 \mu \mathrm{m}$

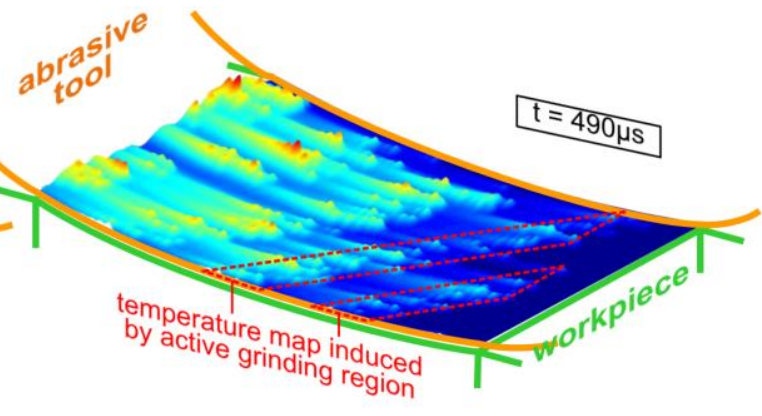

20

temperature $\left({ }^{\circ} \mathrm{C}\right)$

700

Figure 3. An example of the evolution grinding temperature domain with time for tools with PGA calculated by the proposed method when the grain speed is $30 \mathrm{~m} / \mathrm{s}$, the workpiece feed speed is $1.2 \mathrm{~m} / \mathrm{min}$ and the cut depth is $15 \mu \mathrm{m}$ (time $t$ is referenced to the moment when the tool starts to contact the workpiece material)

\subsection{Subsidiary constraint 1 - Ground surface quality (roughness) for tools with PGA}

Although PGA helps to bring coolant into grinding zone to cool down the material, it also results in the missing material removal supposed to happen. The ground surface roughness therefore needs to be modelled to keep the ground surface quality acceptable.

As seen in Fig.4, when a passive grinding region travels over the workpiece material, the ground $2 \mathrm{D}$ surface roughness $\mathrm{R}_{\mathrm{z}}$ is determined by the grains located at both the rear (see Grain 2 in Fig.4) and the front edges (see Grain 1 in Fig.4) of two neighboring active grinding regions, rather than at the PGA bottom (see Grain 3 in Fig.4). Assuming grain 1 has the protrusion $h_{1}$, its trajectory in the coordinate $x_{1} O_{1} y_{1}$ (red curve in Fig.4) then could be expressed as [2]

$$
y_{1}=f_{11}=\frac{1}{\left(2 h_{1}+d_{s}\right)\left(1+v_{\text {grain }} / v_{w}\right)} \cdot\left(x_{1}\right)^{2} .
$$


Similarly, grain 2 trajectory with the protrusion $h_{2}$ (blue curve in Fig.4) is

$$
y_{2}=f_{12}=\frac{1}{\left(2 h_{2}+d_{s}\right)\left(1+v_{\text {grain }} / v_{w}\right)} \cdot\left(x_{2}-\frac{w_{p}}{v_{\text {grain }}} \cdot * v_{w}\right)^{2}+\left(h_{1}-h_{2}\right)
$$

where $v_{w}$ is the material feed speed. Combining Eq.(18) and Eq.(19), it could obtain the $y$ coordinate of the intersection point $\mathrm{Q}$ in reference to the coordinate $x_{1} O_{1} y_{1}$ (denoted as $y_{q}$ ).

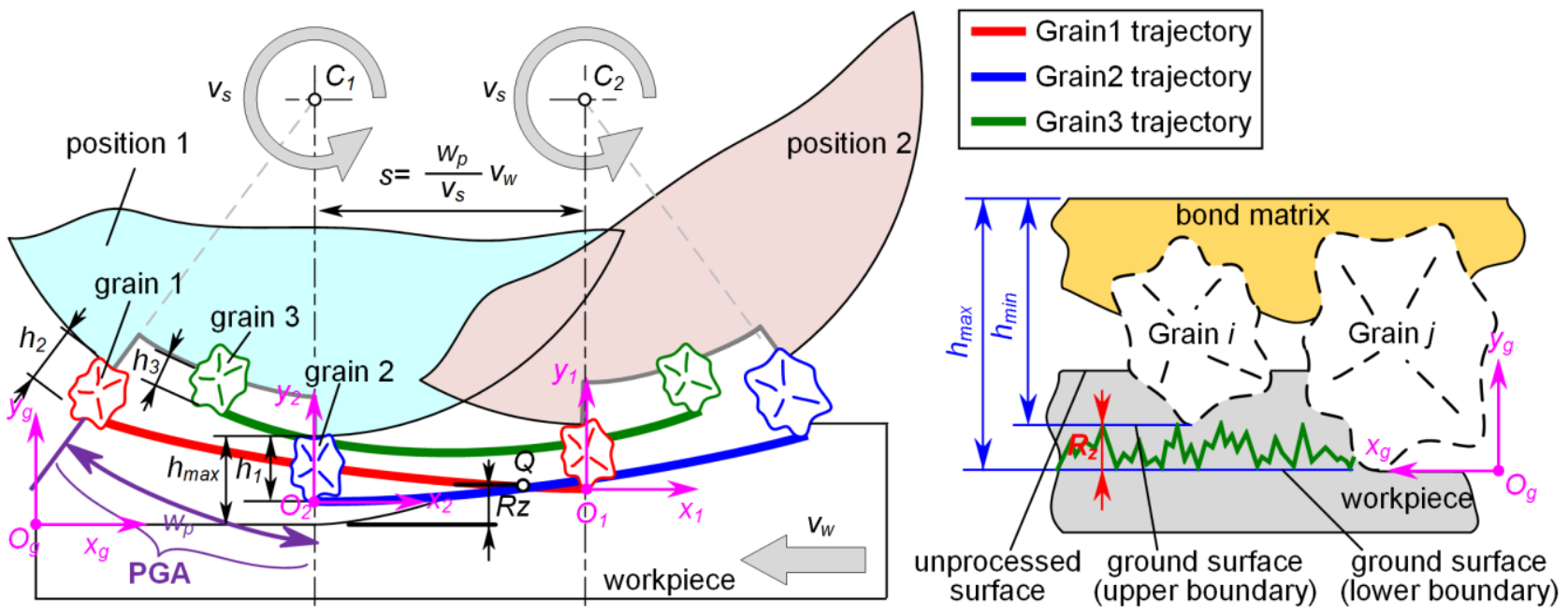

Figure 4. Illustration of the $2 \mathrm{D}$ surface roughness $\mathrm{Rz}$ ground by grinding tools with PGA

As seen in Fig.4, the grain having the biggest and smallest protrusions (denoted as $h_{\max }$ and $h_{\min }$ ) would separately generate the lower and upper boundaries of the ground surfaces, therefore the ground surface roughness $R_{z}$ can be expressed as

$$
R_{z}=f_{13}=y_{q}+\left(h_{\max }-h_{\text {min }}\right)
$$

Considering the maximum-minimum difference of grain protrusions is approximately equal to the maximum-minimum difference of abrasive sizes [2] while the grain size was found to be normal-distributed $[15,16]$, it therefore has

$$
R_{z}=f_{14}=y_{q}+\left(d_{\max }-d_{\min }\right) \cdot \frac{1}{\sqrt{2 \pi} \cdot \sigma} \cdot e^{-\frac{(x-\mu)^{2}}{2 \sigma^{2}}}
$$

where $d_{\max }$ and $d_{\min }$ are separately the maximum and minimum grain diameters, the mean of the distribution $\mu$ is $\left(d_{\max }+d_{\min }\right) / 2$, and the standard deviation $\sigma=\left(d_{\max }+\right.$ $\left.d_{\min }\right) / 6$. Given that the full expression of $R_{z}$ is complex, here $R_{z}$ is simply expressed by

$$
R_{z}=f_{15}\left(w_{p}\right)
$$

\subsection{Subsidiary constraint 2 - Grinding continuity for tools with PGA}


As mentioned above, the periodical tool-material contacts induced by the PGA has the potential to lead to tool-material-machine system chatter [2], therefore the grinding continuity is also mathematically modelled as another constraint in the inverse design method. The grinding continuity here refers to whether the tool and the workpiece material are continuously contacting. As seen in Fig.5, the grinding continuity can be quantified by the variance range of the instantaneous contact width $\Delta$. The smaller $\Delta$ is, the better grinding continuity in grinding the tool has.

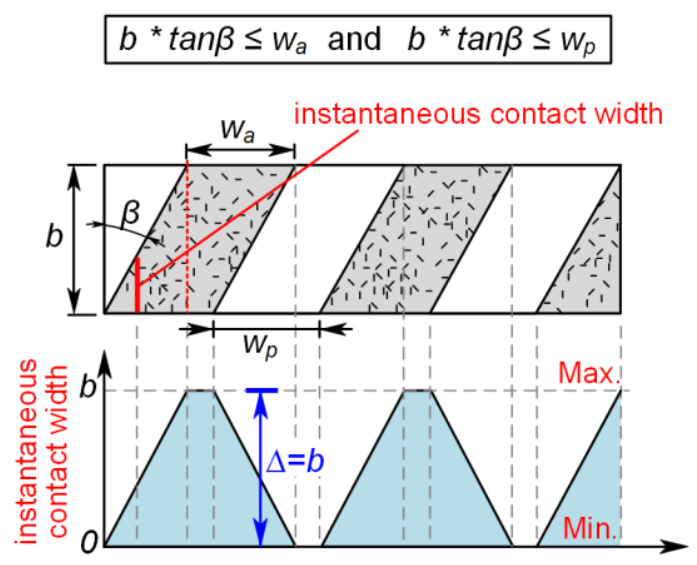

(a)

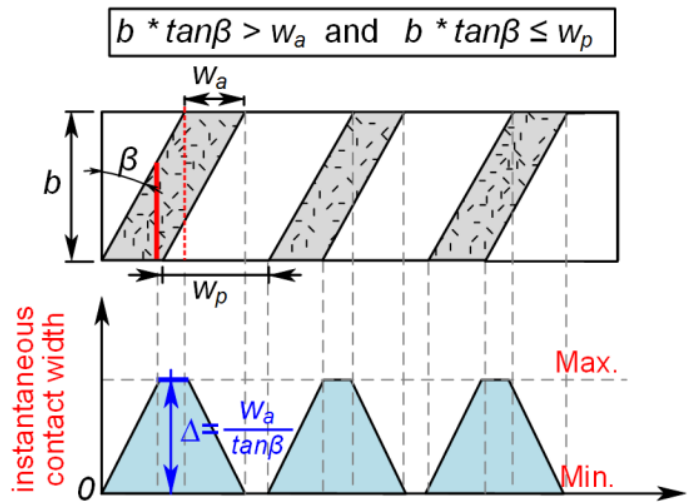

(c)

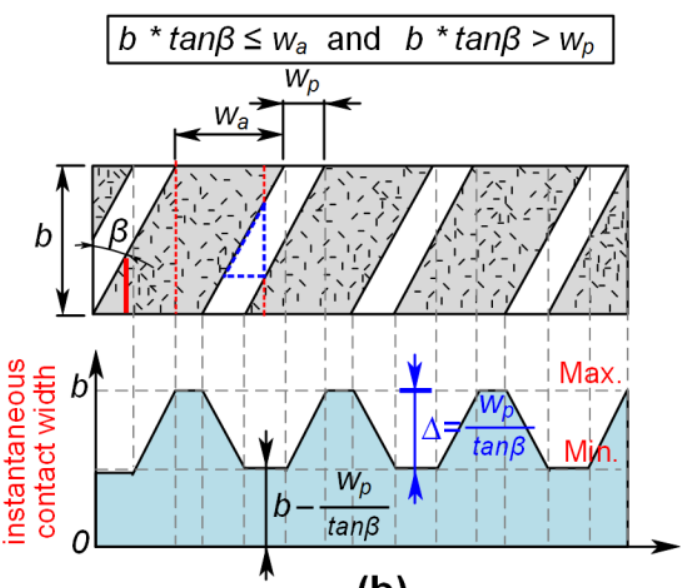

(b)

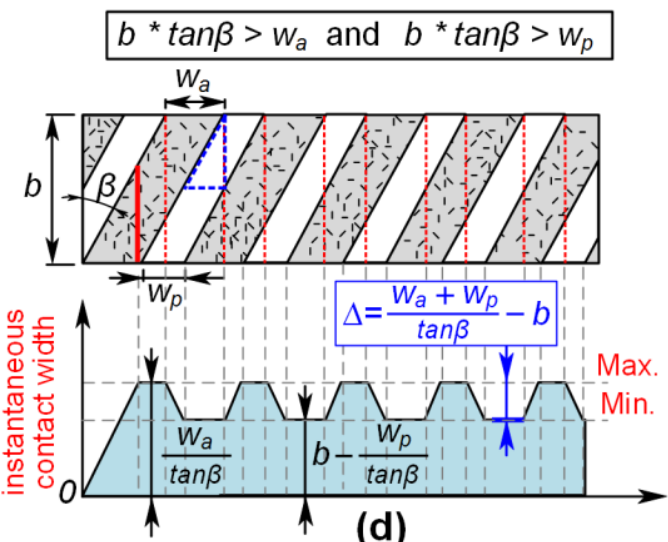

(d)

Figure 5. Illustration of the four possible situations of the instantaneous tool-workpiece contact width when (a) $b * \tan \beta<w_{a}$ and $b * \tan \beta<w_{p}$, (b) $b * \tan \beta<w_{a}$ and $b * \tan \beta>w_{p}$, (c) $b * \tan \beta>w_{a}$ and $b * \tan \beta<$ $w_{p}$, and (d) $b * \tan \beta>w_{a}$ and $b * \tan \beta>w_{p}$. Among these, the case in figure 5 (d) is expected to have the smallest $\Delta$ value, i.e. the limited grinding chatter, because this case has a larger subtrahend $\left(b-w_{p} / \tan \beta\right)$ and a smaller minuend $\left(w_{a} / \tan \beta\right)$ in comparison with other cases

Fig.5 (a) to (d) separately provide four possible $\Delta$ values according to the possible relationships between $w_{p}, \beta, w_{a}$ and $b$. It is not hard to find that, the case in Fig.5 (d) is expected to have the smallest $\Delta$ value, i.e. the limited grinding chatter, because this case has a larger subtrahend $\left(b-w_{p} / \tan \beta\right)$ and a smaller minuend $\left(w_{a} / \tan \beta\right)$. Therefore the 3 rd constraint based on grinding chatter limitation can be expressed as

$$
b * \tan \beta>w_{a} \text { and } b * \tan \beta>w_{p}
$$

where 


$$
\Delta=f_{16}=\frac{\left(w_{a}+w_{p}\right)}{\tan \beta}-b
$$

\subsection{Inverse calculation for PGA geometry parameters}

After the grinding temperature, ground surface roughness and grinding continuity are analytically modelled, the PGA geometry parameters can be inversely solved by using the calculation strategy given in Fig.6. Basically, there are three unknown parameters $\left(w_{a}, w_{p}\right.$ and $\beta$ ) and three established relationships under different cooling situations. It might note that both $f_{15}$ and $f_{16}$ have simple mathematical forms and by introducing them into $f_{8}, f_{9}$, and $f_{10}$ only one unknown variable $\beta$ is left in $T_{m}$.

The elementary function form of the antiderivative of $T_{m}$ is difficult, or impossible, to find because $T_{m}$ is a typical multiple integration having four integral variables $\left(d x^{\prime}, d y^{\prime}, d z^{\prime}\right.$ and $d t^{\prime}$ ) and complex cross terms in the integrand. Hence, a simple yet effective numerical quadrature, the closed Newton-Cotes formulae [20], is employed here. Symbolising the integrand in $T_{m}$ as $f_{17}, T_{m}$ can be approximately expressed as follows based on the Newton-Cotes formulae:

$$
\begin{aligned}
& T_{m}=T_{\text {required }}=\sum_{i=1}^{n g} \int_{0}^{b} \int_{0}^{l_{g}} \int_{0}^{a_{p}} \int_{0}^{t} f_{17} d x^{\prime} d y^{\prime} d z^{\prime} d t^{\prime} \approx \sum_{i=1}^{n g} \frac{b \cdot t \cdot l_{g} \cdot a_{p}}{16} \cdot\left(\left.f_{17}\right|_{x^{\prime}=0, y^{\prime}=0, z^{\prime}=0, t^{\prime}=0}\right. \\
& +\left.f_{17}\right|_{x^{\prime}=0, y^{\prime}=0, z^{\prime}=0, t^{\prime}=t}+\left.f_{17}\right|_{x^{\prime}=0, y^{\prime}=0, z^{\prime}=a_{p}, t^{\prime}=0}+\left.f_{17}\right|_{x^{\prime}=0, y^{\prime}=0, z^{\prime}=a_{p}, t^{\prime}=t}+\left.f_{17}\right|_{x^{\prime}=0, y^{\prime}=l_{g}, z^{\prime}=0, t^{\prime}=0} \\
& +\left.f_{17}\right|_{x^{\prime}=0, y^{\prime}=l_{g}, z^{\prime}=0, t^{\prime}=t}+\left.f_{17}\right|_{x^{\prime}=b, y^{\prime}=0, z^{\prime}=0, t^{\prime}=0}+\left.f_{17}\right|_{x^{\prime}=b, y^{\prime}=0, z^{\prime}=0, t^{\prime}=t}+\left.f_{17}\right|_{x^{\prime}=0, y^{\prime}=l_{g}, z^{\prime}=a_{p}, t^{\prime}=0} \\
& +\left.f_{17}\right|_{x^{\prime}=0, y^{\prime}=l_{g}, z^{\prime}=a_{p}, t^{\prime}=t}+\left.f_{17}\right|_{x^{\prime}=b, y^{\prime}=0, z^{\prime}=a_{p}, t^{\prime}=0}+\left.f_{17}\right|_{x^{\prime}=b, y^{\prime}=0, z^{\prime}=a_{p}, t^{\prime}=t}+\left.f_{17}\right|_{x^{\prime}=b, y^{\prime}=l_{g}, z^{\prime}=0, t^{\prime}=0} \\
& +\left.f_{17}\right|_{x^{\prime}=b, y^{\prime}=l_{g}, z^{\prime}=0, t^{\prime}=t}+\left.f_{17}\right|_{x^{\prime}=b, y^{\prime}=l_{g}, z^{\prime}=a_{p}, t^{\prime}=0}+\left.f_{17}\right|_{x^{\prime}=b, y^{\prime}=l_{g}, z^{\prime}=a_{p}, t^{\prime}=t}
\end{aligned}
$$

Note that Eq.(25) is a typical quadratic polynomial in regard of $\beta$, and therefore probably more than one solutions might be obtained. Therefore, the solutions should be substituted back into $f_{4}, f_{5}, f_{6}, f_{7}, f_{8}, f_{9}, f_{10}, f_{15}$ and $f_{16}$ to confirm whether the tools with the calculated $P G A$ can meet the requirement.

Please also note that, for some cases with special tool performance requirements, no solutions of $w_{a}, w_{p}$ and $\beta$ can be found. This means no matter what dimension the PGA geometry has the requirement cannot be satisfied, indicating the proposed inverse method 
might also be used to find the tool performance limitations in terms of grinding temperature, ground surface quality and grinding continuity.

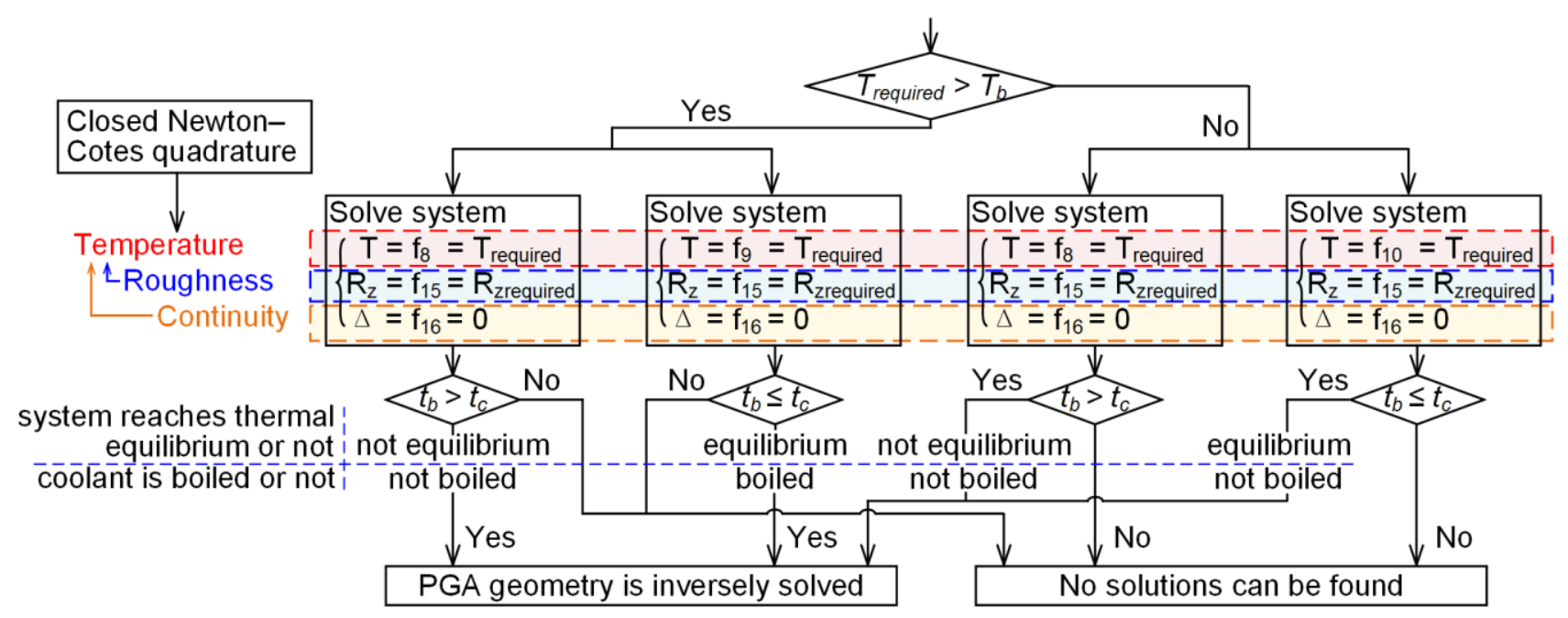

Figure 6. Flowchart of the inverse calculation of the PGA geometry parameters

\section{Materials and Methods}

The proposed inverse method is validated by solving the PGA geometries based on two different sets of required grinding temperature $T_{\text {required }}$, ground surface roughness $R z_{\text {required }}$, and grinding continuity (quantified by the variance range of normal-tangential resultant grinding force per unit tool width $\left.\Delta_{\text {required }}\right)$. In Case $1, R z_{\text {required-1 }}$ is $2.5 \mu \mathrm{m}$, $T_{\text {required }-1}$ is $620^{\circ} \mathrm{C}$, and $\Delta_{\text {required }-1}$ is $3 \mathrm{~N} / \mathrm{mm}$, while in Case $2, R z_{\text {required-2 }}$ is $4.5 \mu \mathrm{m}$, $T_{\text {required }-2}$ is $550{ }^{\circ} \mathrm{C}$, and $\Delta_{\text {required-2 }}$ is $1.5 \mathrm{~N} / \mathrm{mm}$. To prove the method accuracy in a wide range of grinding conditions, the grinding parameters in the two cases are also set different: in Case $1, v_{\text {grain }-1}$ is $30 \mathrm{~m} / \mathrm{s}, v_{w-1}$ is $1.2 \mathrm{~m} / \mathrm{min}$, and $a_{p-1}$ is $15 \mu \mathrm{m}$, while in Case 2, $v_{s-2}$ is $25 \mathrm{~m} / \mathrm{s}, v_{w-2}$ is $2 \mathrm{~m} / \mathrm{min}$, and $a_{p-2}$ is $10 \mu \mathrm{m}$. Other given parameters include the tool diameter $d_{s}$ is $150 \mathrm{~mm}$, the abrasive number $M$ is $\# 80$ and the tool width $b$ is $10 \mathrm{~mm}$. Considering the wide usage in various industries, steel AISI 1055 blocks with the dimension of $80 \mathrm{~mm}^{*} 10 \mathrm{~mm}^{*} 5 \mathrm{~mm}$ are used as the workpiece material, with the specific heat capacity $c$ of $477 \mathrm{~J} \cdot \mathrm{kg}^{-1} \cdot \mathrm{K}^{-1}$, the thermal diffusivity $\alpha$ of $3.3 \mathrm{E}^{-6} \cdot \mathrm{m}^{2} \cdot \mathrm{s}^{-1}$, the density $\rho$ of $7840 \mathrm{~kg} \cdot \mathrm{m}^{-3}$, and the thermal conductivity $h$ of $49.8 \mathrm{~W} \cdot \mathrm{m}^{-1} \cdot \mathrm{K}^{-1}$.

Due to the limited tool wear thanks to the non-contact nature and high geometrical flexibility to machine complex shapes, waterjet machining is used to produce the calculated PGA geometries on two conventional resin-bonded $\mathrm{Al}_{2} \mathrm{O}_{3}$ abrasive tool surfaces (WA80L5V). Before this, the two tools are dressed by a single-diamond with the dressing ratio of -0.6 and dressing depth of $10 \mu \mathrm{m}$ (10 times). As seen in Fig.7 (a), the PGA fabrication is performed on a 5 -axis waterjet machine tool (Ormond), with the jet orifice diameter of $0.3 \mathrm{~mm}$, the focusing 
tube (nozzle) diameter of $1 \mathrm{~mm}$, the nozzle-to-surface stand-off distance of $0.5 \mathrm{~mm}$, and the pump pressure of $10.34 \mathrm{MPa}$ (1500 psi) (KMT streamline SL-V100D). The obtained PGA geometries are measured by the white light interferometer (Bruker GT-I) to guarantee the angle and dimension. Fig.7 (b) shows the produced two abrasive tools with the PGA geometries calculated by the proposed inverse method based on the two different sets of required tool performances. Besides, a conventional abrasive tool without PGA (with completely the same basic properties, e.g. tool diameter, abrasive type and size) also is used in the grinding trials to provide the reference.

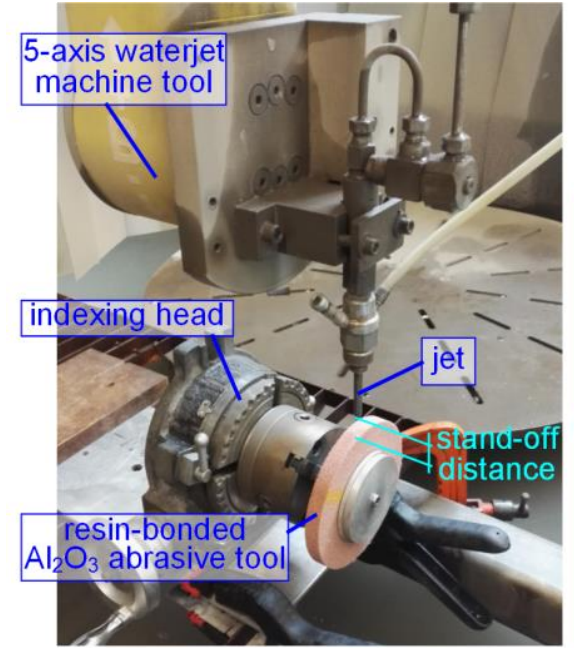

(a)

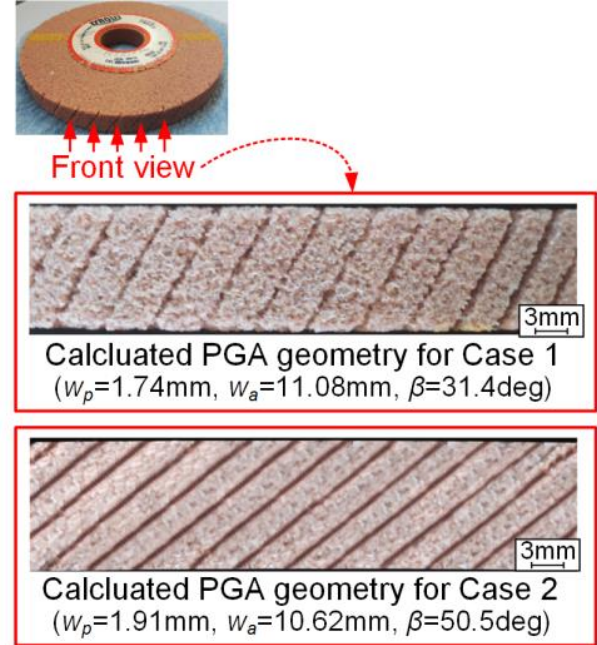

(b)

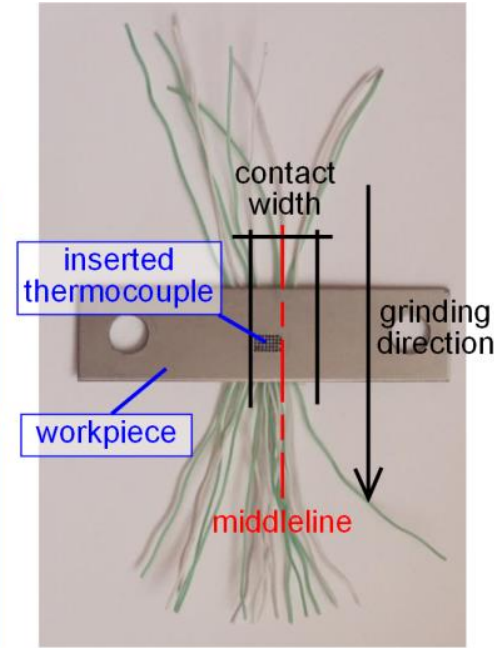

(c)

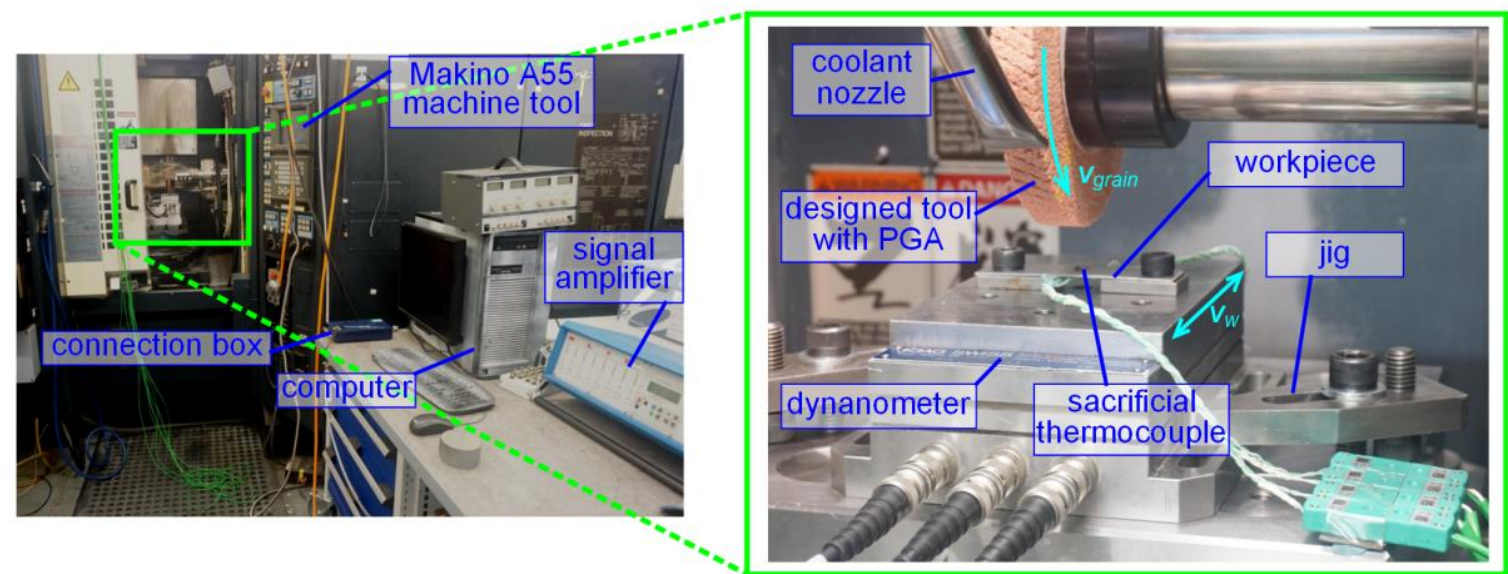

(d)

Figure 7. (a) Fabrication of the PGA geometry by using the 5-axis waterjet machine tool, (b) the produced abrasive tools with the PGA geometries designed by the proposed inverse method based on the two different sets of required tool performances, (c) the workpiece having inserted thermocouple used to measure the temperature of the tool-workpiece interface in grinding, and (d) experiment setup of the grinding trials by using the 5-axis machine tool

As seen in Fig.7 (c), the grinding temperature is measured by the experimentally-validated inserted sacrificial thermocouple technique [3] by using the data logger (GW Model 100) with the sampling rate of $200 \mathrm{kHz}$. The water-based emulsified coolant (Hocut 3380 with $5 \%$ concentration) is used in all the trials with the density $\rho_{c}$ of $7840 \mathrm{~kg} \cdot \mathrm{m}^{-3} 0.92$, the specific 
heat capability $c_{c}$ of $415 \mathrm{~J} \cdot \mathrm{kg}^{-1} \cdot \mathrm{K}^{-1}$, the initial temperature $T_{c 0}$ of $20^{\circ} \mathrm{C}$, and the boiling point $T_{b}$ of $580^{\circ} \mathrm{C}$. After the trials, the ground surface roughness is obtained by measuring the ground surface topography by the 3D profilometer (ContourGT Optical Profiler) and randomly selecting three cross-section profiles.

As seen in Fig.7 (d), all the grinding trials are performed on a 5-axis machine tool (Makino A55). During the trials, the grinding forces are captured by the 4-component dynamometer (Kistler 9257) with the sampling rate of $100 \mathrm{kHz}$.

One note here is that the employed temperature measurement technique was based on the sacrificial two-pole standard K-type Thin Film Thermocouples (TFTC) (OMEGA 88000). The working principle is [3]: before the grinding trials, two poles of the thermocouple (insulated by the perfluor-oalkoxy resin jackets) were split apart and inserted into the blind holes of the workpiece with the protrusion height of around 15 20 $\mu \mathrm{m}$. When the grinding wheel passed the workpiece, the two pole materials were smeared together and formed the junction of the thermocouple so that the grinding zone temperature can be measured.

As seen in Fig.8 (a), before the trials, the calibration of the TFTC was performed by: (1) fill the container with oil and heat it to a required temperature, (2) twist the split two poles of the thermocouple together, place the junction into the oil, and connect each lead of the voltmeter to the other end of the two poles, (3) when the voltage stops fluctuating, record the voltmeter reading $x_{r}$, i.e. the electric potential difference resulted from the oil temperature, (4) put the probe of the standard electronic thermometer into the oil to capture the oil temperature $y_{r}$, (5) increase the oil temperature to another temperature and repeat the above procedures from the step (3), and (6) linearly fit the obtained data $\left(x_{r}, y_{r}\right)$ by the least square method so that all the captured voltage signals can be converted into temperature values. The fitting result of the used thermocouple is given in Fig. 8 (b).

Besides, after each grinding trial, the formed thermocouple junctions were not only carefully observed by a microscope to guarantee the working status of the formed junction but also quantitatively validated by using a standard electronic thermometer as the benchmark. Fig. 8 (c) clearly shows that, the originally split two poles were smeared together when the wheel passed the workpiece and the thermocouple measure junction was formed. Fig.8 (d) illustration the experimental setup of the accuracy validation of the formed junction after the grinding trials. The comparisons of the temperature signals separately captured by the formed junction and the thermometer are compared in Fig. 8 (c), (d), and (e) when the temperature was separately increased to $100{ }^{\circ} \mathrm{C}, 200{ }^{\circ} \mathrm{C}$, and $300^{\circ} \mathrm{C}$. It can find that, the temperature measured by the formed junction was close to the thermometer value in the 
three cases. The relative differences were separately $0.6^{\circ} \mathrm{C}, 1.1^{\circ} \mathrm{C}$, and $1.5^{\circ} \mathrm{C}$, proving the measurement accuracy of the proposed technique to a large extent.

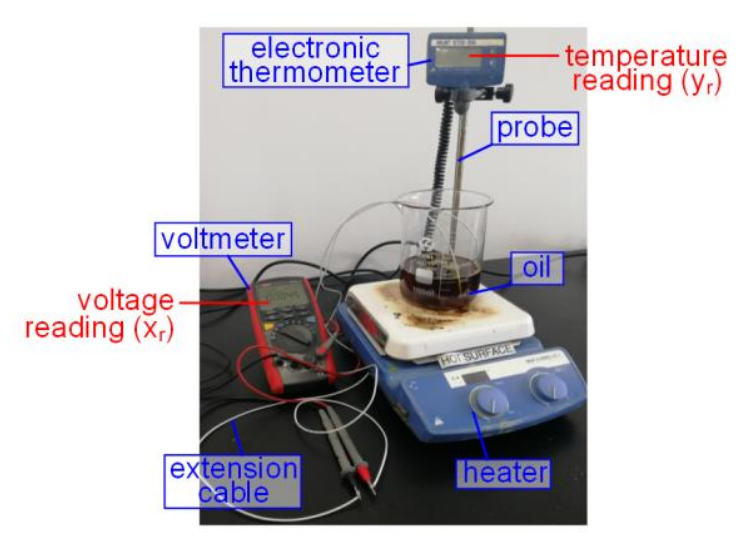

(a)

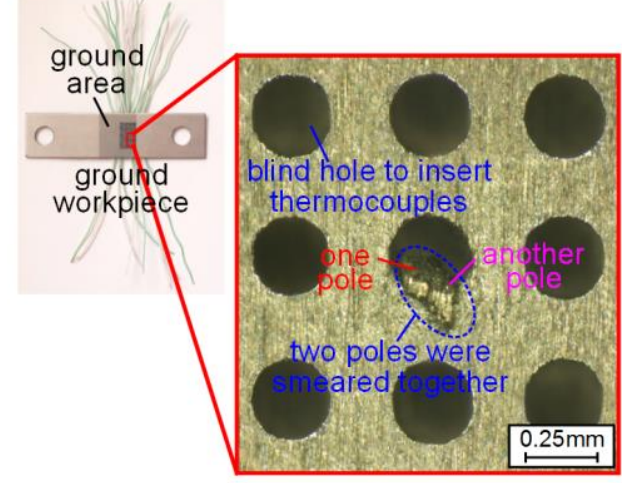

(c)

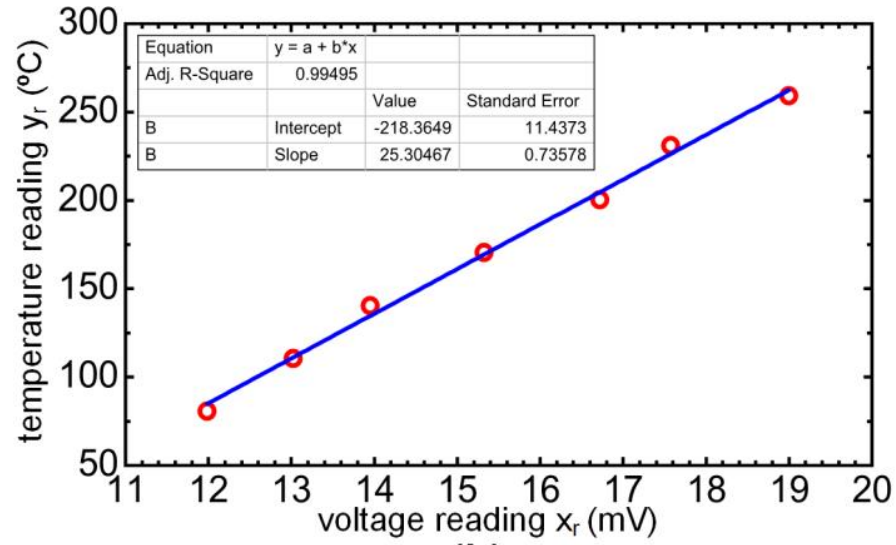

(b)

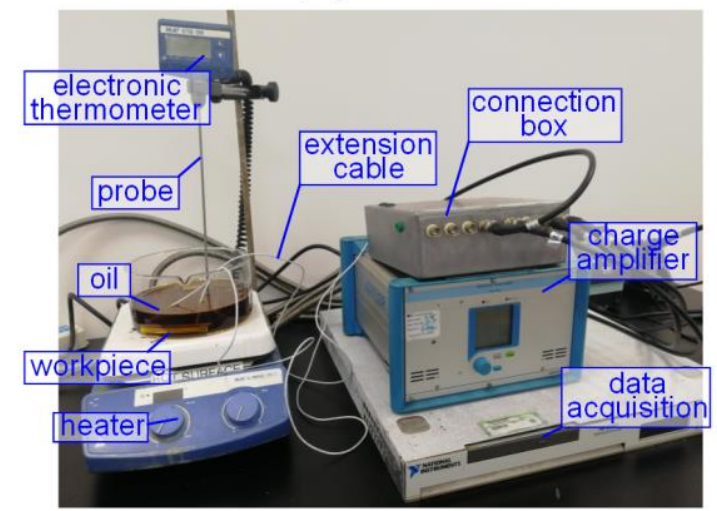

(d)

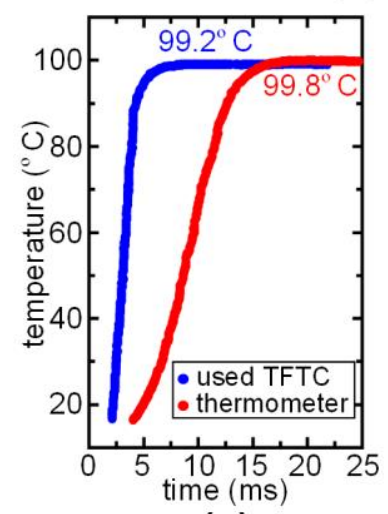

(e)

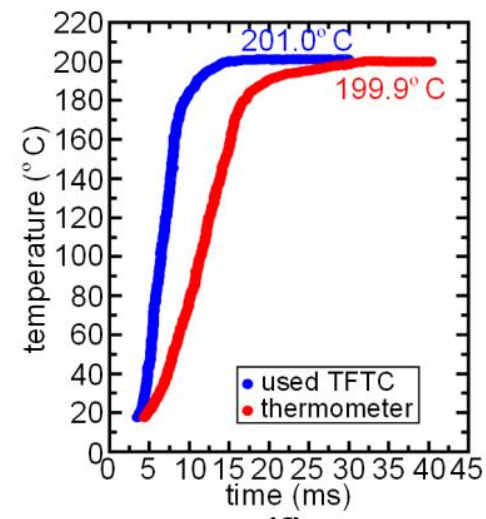

(f)

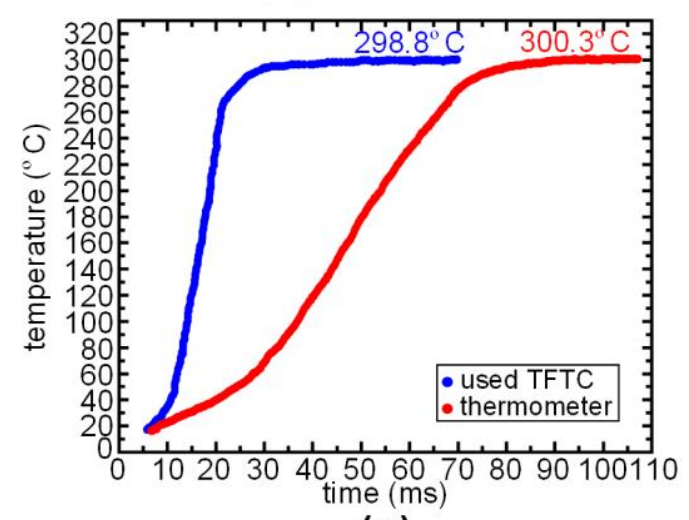

(g)

Figure 8. (a) The experimental setup and (b) the linear fitting result in the calibration of the employed thermocouples, (c) the formed junction between the two poles of the thermocouple observed by the microscope, (d) the experimental setup of the accuracy validation of the formed junction, and the temperature signals separately captured by both the formed junction after grinding and the electronic thermometer when the temperature is increased to (c) $100{ }^{\circ} \mathrm{C}$, (d) $200^{\circ} \mathrm{C}$, and (e) $300^{\circ} \mathrm{C}$ 


\section{Results and discussion}

\subsection{Reduction of thermal effects on workpiece surfaces using inversely designed abrasive tool with PGA}

Fig.9 (a) gives the grinding temperature by using the inversely designed tools under the given grinding parameters. It can find the measured maximum grinding temperature is 7 Celsius lower than the requirement in Case 1, while 6 Celsius lower in Case 2, i.e. the tools in both Case 1 and 2 meet the temperature requirement, even considering the standard error.

The encouraging result can also be found in Fig.9 (b). The measured ground surface roughness Rz in Case 1 and 2 is separately $0.3 \mu \mathrm{m}$ and $0.4 \mu \mathrm{m}$ lower than the requirements, although the ground surfaces by the tools with PGA are not as smooth as the ones by the conventional tool.

Considering the instantaneous contact width is difficult to measure in trials, the grinding continuity in the experiments are quantified by the variance range of grinding forces per unit tool width (explained in Section 3.3) and results are given in Fig.9 (c). It demonstrates that the force fluctuation in Case 1 and 2 is separately $0.6 \mathrm{~N} / \mathrm{mm}$ and $0.2 \mathrm{~N} / \mathrm{mm}$ smaller than the requirement, indicating the acceptable grinding continuity for the tools with calculated PGA. Besides, the PGA geometry parameters in both Case 1 and 2 satisfies the relationship $b$ * $\tan \beta>w_{p}$, indicating the minimum instantaneous tool-workpiece contact width cannot be zero and therefore can achieve relatively good grinding continuity. The PGA geometries in Case 1 and Case 2 separately correspond to the situations given in Fig.5 (b) and Fig.5 (d), which also explained why the grinding force fluctuation in Case 1 is larger than the one in Case 2 (Case 1 has larger maximum instantaneous contact width).

Another observation in Fig.9 (a) is the pronounced maximum temperature reduction of $61^{\circ} \mathrm{C}$ in Case 1 and $125^{\circ} \mathrm{C}$ in Case 2 by designing discontinuities on the tool surfaces, in comparison with the conventional tool with continuous periphery surface. These two reduction values can also match the temperature reduction based on the thermal energy that the coolant took away from the material as follows, proving the method accuracy to a certain extent.

Taking Case 1 as an example, it might be commented based on the result that, the coolant transported by the PGA is boiled from 0 to $t_{b}=124 \mu$ s and then starts to vaporization at the coolant-material contact interface from $t_{b}=124 \mu \mathrm{s}$ to $t_{c}=283 \mu \mathrm{s}$, because $t_{c}$ is longer than $t_{b}$ and the measured temperature in trials $T=603^{\circ} \mathrm{C}$ is higher than the cooling boiling point $T_{b}=340^{\circ} \mathrm{C}$. Therefore, for each revolution of the tool in grinding, the thermal energy that is taken away from the material to increase the transported coolant temperature until boiling (denoted as $E_{b}$ ) is 


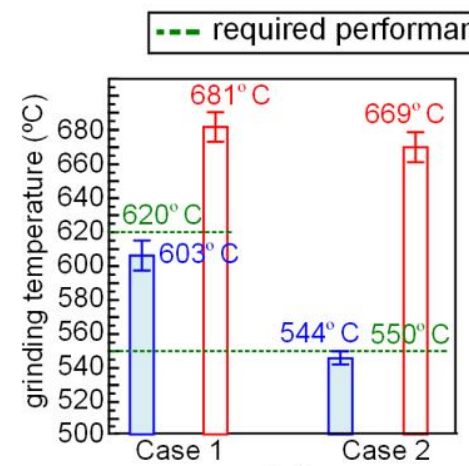

(a)

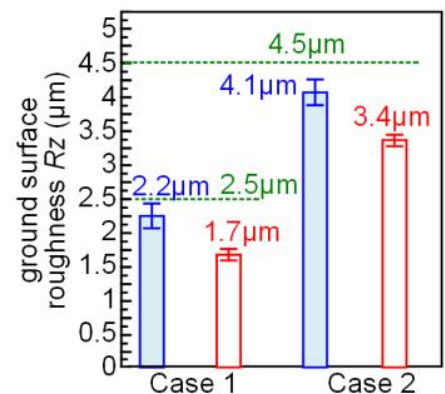

(b)

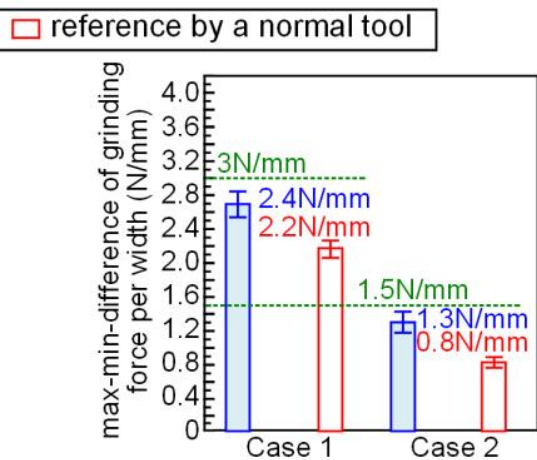

(c)

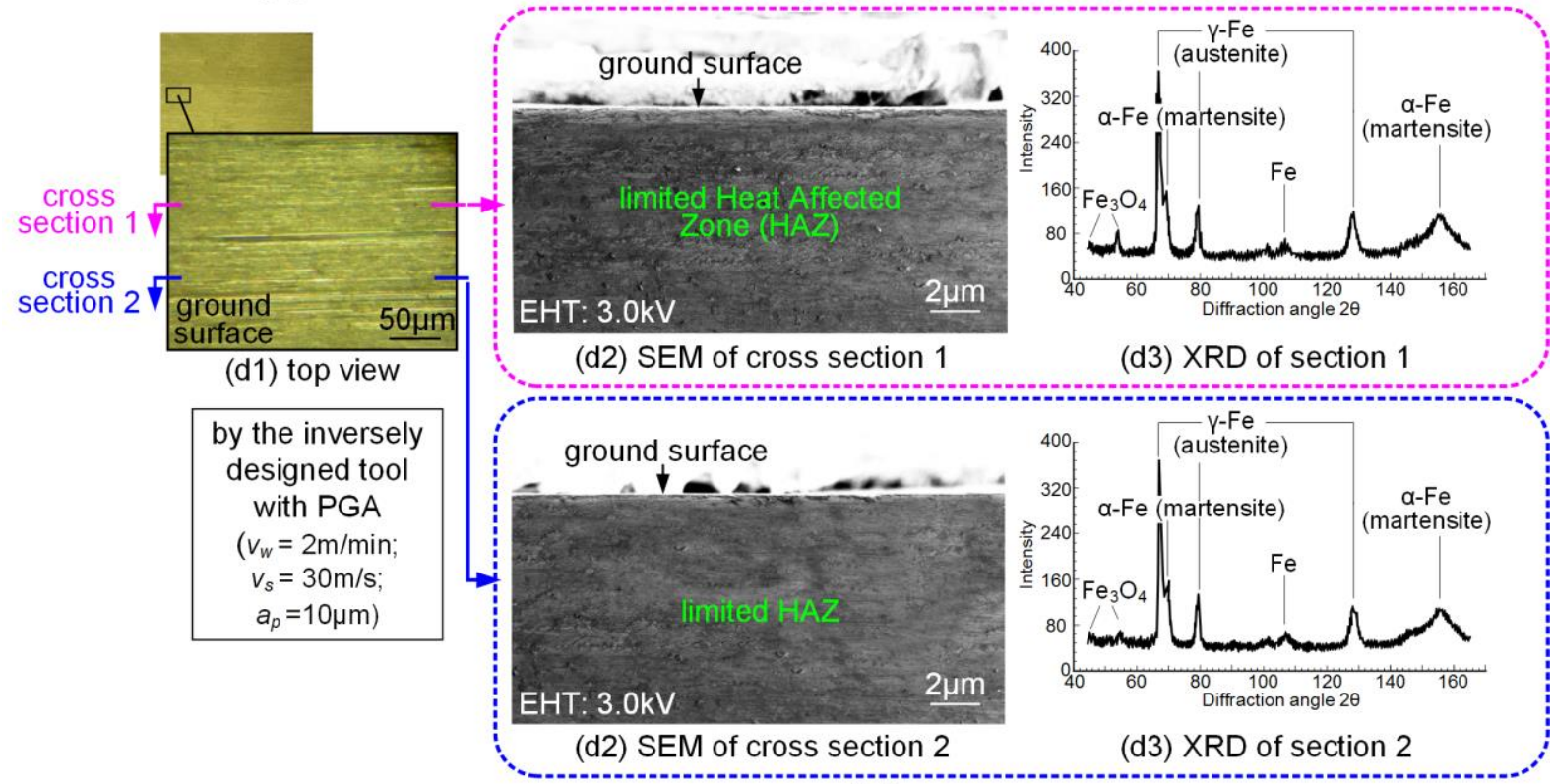

(d)

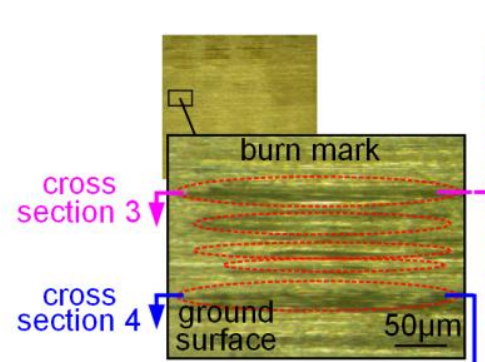

(e1) top view

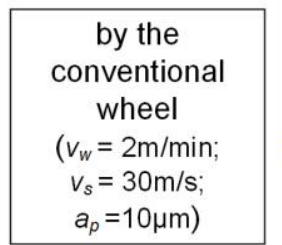

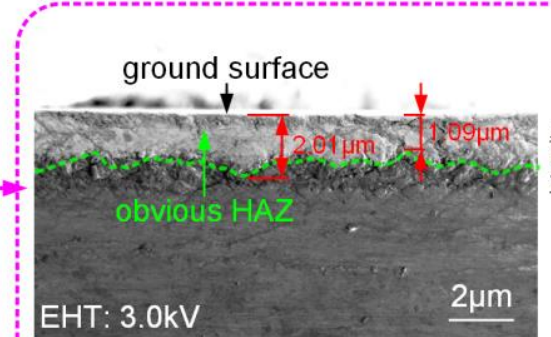

(e2) SEM of cross section 3

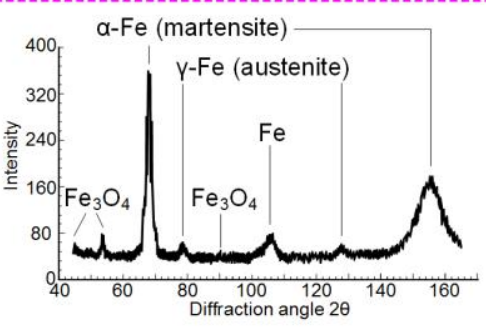

(e3) XRD of section 3

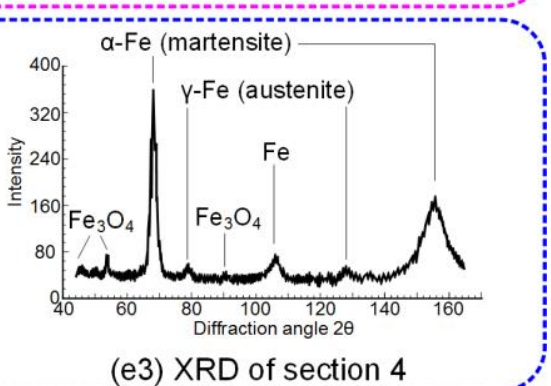

(e3) XRD of section 4

(e2) SEM of cross section 4

(e)

Figure 9. The comparisons of (a) grinding temperature, (b) ground surface roughness $\mathrm{Rz}$, (c) variance range of the grinding forces per unit tool width, and the ground surface morphology in terms of top view (d1 for the inversely-designed wheel and $\mathrm{e} 1$ for the conventional wheel), SEM micrographs of two randomly selected cross sections ( $\mathrm{d} 2$ for the inversely-designed wheel and e2 for the conventional wheel), and XRD spectrum analysis (d3 for the inversely-designed wheel and e3 for the conventional wheel) 


$$
E_{b}=\rho_{c} \cdot H_{p g a} \cdot b \cdot w_{p} \cdot \pi \cdot \frac{d_{s}}{\left(w_{a}+w_{p}\right)} \cdot c_{c} \cdot\left(T_{b}-T_{c 0}\right)=4.23 \mathrm{~J}
$$

while the thermal energy that is taken away from the material to continuously evaporate the boiling coolant (denoted as $E_{e}$ ) is

$$
E_{e}=\rho_{c} \cdot H_{p g a} \cdot b \cdot w_{p} \cdot \frac{\left(t_{c}+t_{b}\right) \cdot v_{\text {grain }}}{\left(w_{a}+w_{p}\right)} \cdot \chi=9.4 \mathrm{~J}
$$

where $\chi$ is the coolant evaporation heat (i.e. the required energy to evaporate $1 \mathrm{~kg}$ coolant). Therefore, when the tool grinds the material in one pass, the total thermal energy that is taken away by coolant $E_{t}$ is

$$
E_{t}=\left(E_{b}+E_{e}\right) \cdot \frac{60000 \cdot v_{\text {grain }}}{\pi \cdot d_{s}} \cdot \frac{l}{v_{w}}=530.2 \mathrm{~J}
$$

when the one pass length $l$ is $10 \mathrm{~mm}$ (see the workpiece dimension in Section 4). Hence, this thermal energy can result in the material temperature reduction $\Delta T$ of

$$
\Delta T=\frac{E_{t}}{c_{m} \cdot m_{m}}=55.6^{\circ} \mathrm{C}
$$

which is close to the experimentally measured decrease of $61^{\circ} \mathrm{C}$.

It might conclude from Eqs. (26-29) that, the dominant cooling mechanism is the boiled coolant evaporation if the critical conditions $\left(T_{e}>T_{b}\right.$ and $\left.t_{b} \leq t_{c}\right)$ can be satisfied, because in Case 1 the evaporation contributes $69.0 \%(9.4 \mathrm{~J} /(9.4 \mathrm{~J}+4.23 \mathrm{~J}))$ to the ground surface temperature reduction. If the condition is not satisfied, heating the coolant by heat transfer at the coolant-material interface until it boils would be the main cooling mechanism.

More evidences of the effective thermal effect reduction by using the inversely-designed wheel can be observed in the comparison between Fig.9 (d) and (e). The optical micrograph of the surface ground by the wheel with PGA (Fig.9 d1) shows very limited region having heat-induced marks, while obvious burn marks manifested by the large-scaled dark stripes along the grinding direction can be easily recognised on the surface ground by the conventional wheel (Fig.9 e1). The dark color of the burn marks to a large extent indicates the oxidizing during grinding, and the main reason of it is believed to be the high grinding temperature induced by the conventional wheel.

More convincing evidences can be the SEM micrographs of the workpiece cross sections (two sections were observed for each workpiece). The conventional wheel results in the obvious Heat Affected Zone (HAZ) in both the section 3 and 4 (Fig.9 e2) while nearly no HAZ can be found in the section 1 and 2 (Fig.9 d2). Although the HAZ thickness in Fig.9 (e2) is 
only 1.09 2.01 $\mu \mathrm{m}$ and 1.47 2.06 $\mu \mathrm{m}$ separately in two randomly selected sections, the HAZ can still easily lead to short fatigue life and unfavorable tensile residual stress because the fine crystalline grains in the HAZ were reported to be of high brittleness [2]. Considering the fact that HAZs were resulted from mechanical and thermal loads [2] but the mechanical loads tended to be close in this trial (as grinding parameters were kept the same), it would be reasonable to expect the better ground surface integrity due to the superior thermal performance of the inversely-designed wheel.

Except for the qualitative observation above, the quantitative XRD analysis for two random spots in each section also provides consistent evidences. For the surface ground by the conventional wheel (see Fig.9 e3), the pronounced $\alpha$-Fe peak can be clearly seen, which refers to the hard and brittle martensite, while for the one ground by the wheel with PGA (Fig.9 d3), the peak shifts to the $\mathrm{Y}$-Fe phase, referring to the austensite constituent. These different microstructural components confirm the presence of the HAZ in Fig.9 (e2) from metallurgical aspect. Considering the coolant cooling and the self-quenching effect (hightemperature ground surface is quenched by the cooler bulk material [2]) would be similar in both two cases, the above XRD spectrums in Fig.9 (d3) and (e3), to a large extent, indicate the lower grinding temperature for the wheel with PGA.

\subsection{Optimisation of the generic PGA geometry calculated by the inverse method}

The proposed inverse method is suggested based on the tool with the generic form of PGA as Fig.1 (b), therefore there might have some practical shortcomings of the inverselydesigned PGA geometry, e.g. the undesired load distribution induced by the tool-workpiece interaction. Hence, further optimisation work might need to be performed after $w_{a}, w_{p}$ and $\beta$ are solved by the proposed inverse method.

Fig.10 (a) gives an optimisation example. In the figure, the generic PGA geometry having the calculated $w_{a}, w_{p}$ and $\beta$ is named as the prototype. It is not hard to imagine that the prototype might probably lead to unfavorable axial grinding force $\left(F_{a}\right.$ in Fig.10a) due to the tilted interaction between the active-grinding region edges and the material.

To fix this, the prototype is transformed into the optimised form 1 as Fig.10 (a), by which the axial forces resulted from the left $\left(F_{a-l e f t}\right.$ in Fig.10a) and right $\left(F_{a-r i g h t}\right.$ in Fig.10a) parts in reference to the centerline would counteract with each other. More importantly, the optimised form 1 is anticipated to have the same superior cooling performance as the prototype, because the form 1 has the equal area of the passive grinding region and therefore similar coolant transportation ability. Following the similar idea, the form 1 can be further optimised 
to the form 2 as seen in Fig.10 (a). Again, the form 2 might have the similar cooling performance as the form 1, but the form 2 has better manufacturability because the relatively short peripheral length of each individual PGA is easier to be produced by waterjet machining.

Grinding trials have been also performed to evaluate performances of the three tools including the prototype, the optimised form 1 and 2 (see Fig.10b). The results indicate that, the optimised form 1 and 2 are as effective as the prototype not only to reduce the high grinding temperature (Fig.10c), but also to decrease the undesired axial forces (Fig.10d). These results also to some extent prove both the importance of the prototype calculated by the proposed method and the method accuracy.

In fact, the inverse design of discontinuities on the conventional tool surfaces based on the specific required performances can be considered as an open yet very important topic, even though the present work fills the gap to a certain extent. Future research might include the inverse design of PGA geometry for free-form lens surfaces and sculptured surfaces of the 3D-printed products, and also the inverse design of the ball end or cup grinding tools where the tool cross section profile is not flat.
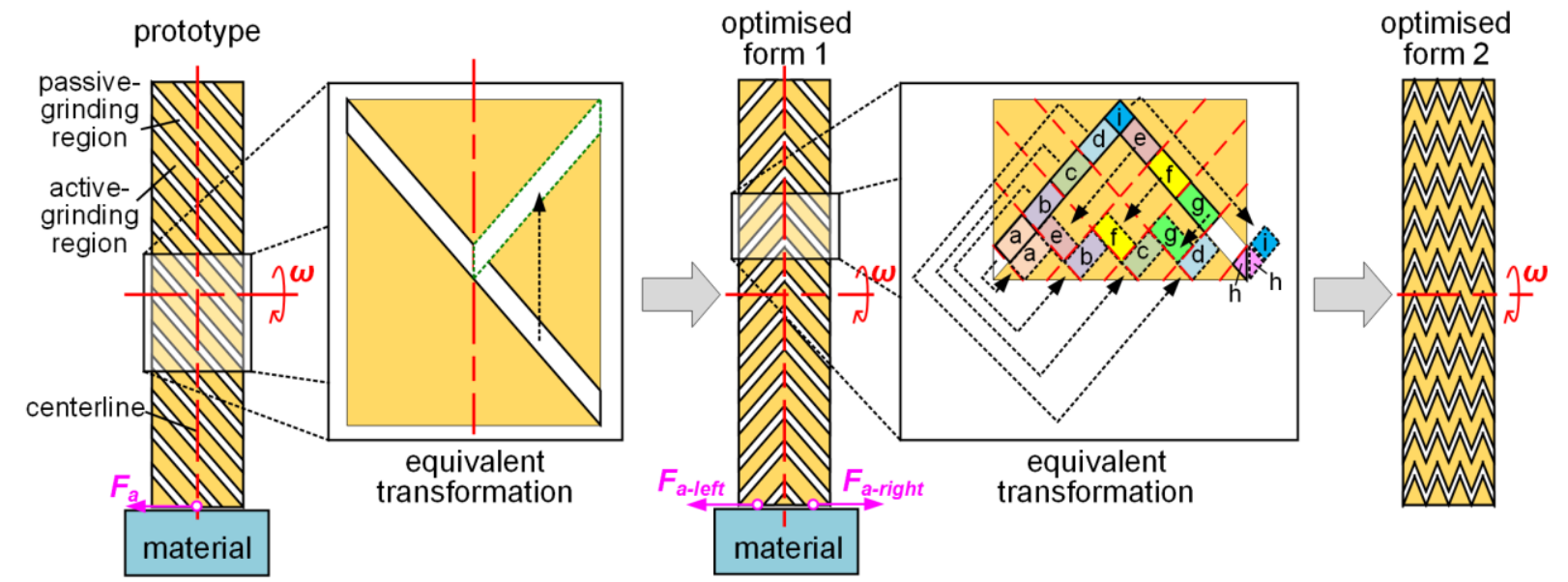

(a)

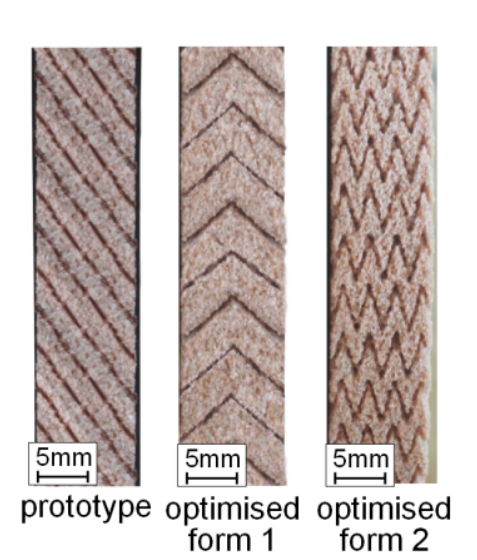

(b)

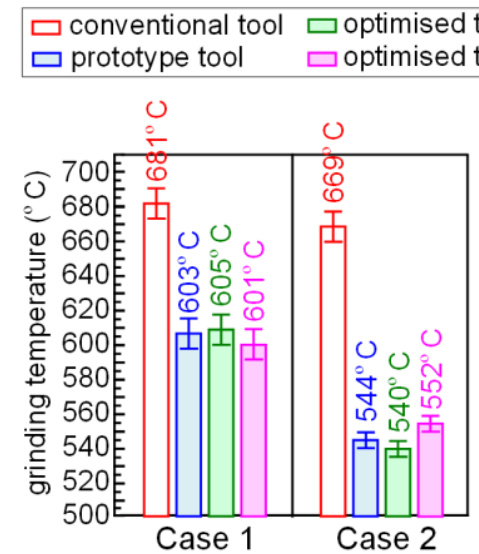

(c)

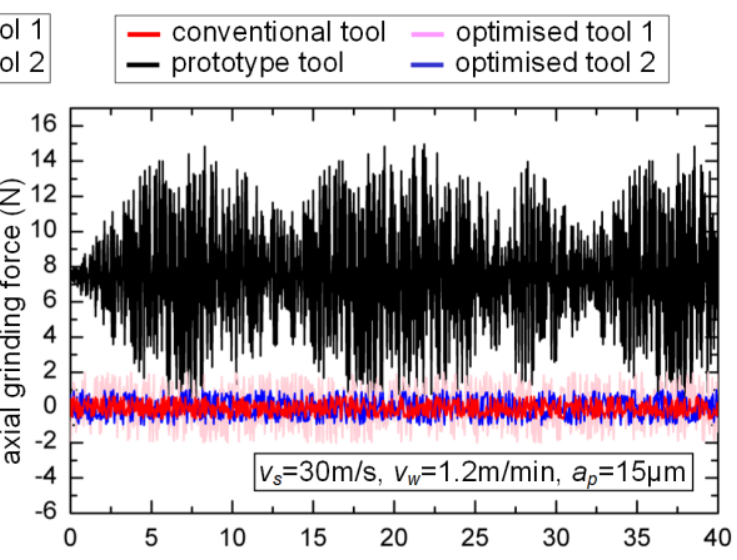

(d)

Figure 10. An example of further optimisation of the inverse method (PGA geometry optimisation). (a) The 
equivalent transformation of PGA geometry from the calculated prototype to the optimised form 1 and 2, (b) the produced tools, experimentally-measured (c) grinding temperature and (d) axial grinding force for the conventional, prototype, and optimised tools

\subsection{The morphology of grinding wheels with PGA after grinding trials}

Except for superior thermal performance, the morphology of the grinding wheels with PGA after the grinding trials also needs to be experimentally studied because the wheel wear behavior would influence the geometrical size consistency of PGA during the grinding operation and therefore further affect the wheel performances during the whole period of grinding process.

Fig.11 (a) and (b) separately give the wheel morphologies before and after the grinding trials where the workpiece volume of $20 \mathrm{~mm}^{3}$ was removed (after 20 grinding passes where $v_{s-2}$ is $25 \mathrm{~m} / \mathrm{s}, v_{w-2}$ is $2 \mathrm{~m} / \mathrm{min}$, and $a_{p-2}$ is $10 \mu \mathrm{m}$, i.e. $1 \mathrm{~mm}^{3}$ material removal per pass). It can find that, both the included angle of the neighboring PGA (39.5) and the PGA width (1.74 $\mathrm{mm}$ ) kept constant when 20 passes of grinding operation were performed. The tip of the PGA (see i in Fig.11a and b) also kept sharp after grinding trials and no observable wear or grain pull-off can be found. Considering the employed material removal rate of $200 \mathrm{~mm} 3 / \mathrm{min}$ (wheel width of $10 \mathrm{~mm}, v_{w-2}$ of $2 \mathrm{~m} / \mathrm{min}$, and $a_{p-2}$ of $10 \mu \mathrm{m}$ ) falls into the common range of industrial grinding [2], the above observation can prove the acceptable wear resistance of the wheels with PGA to a large extent.

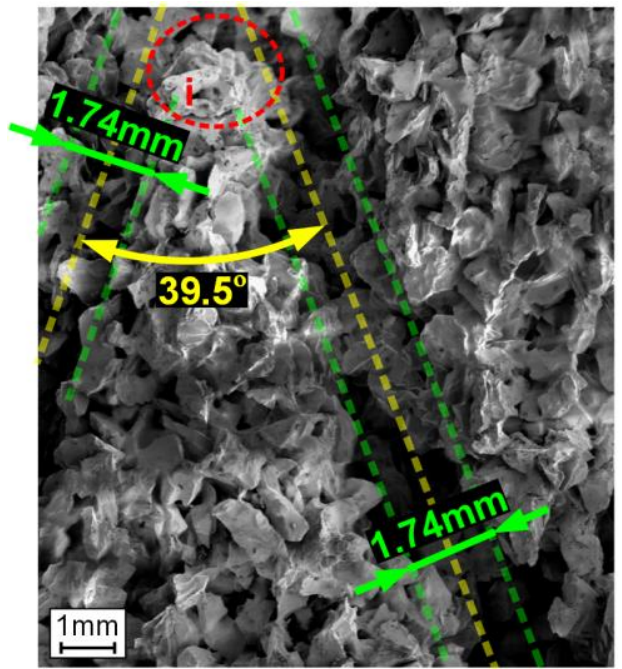

(a)

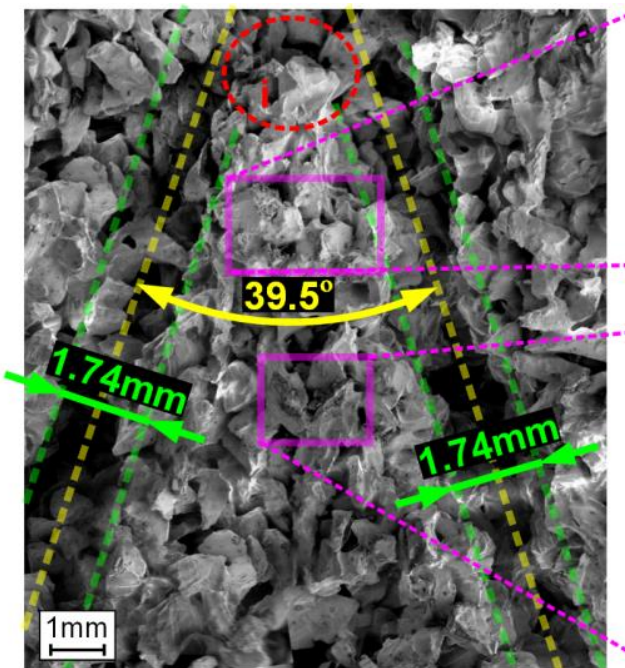

(b)

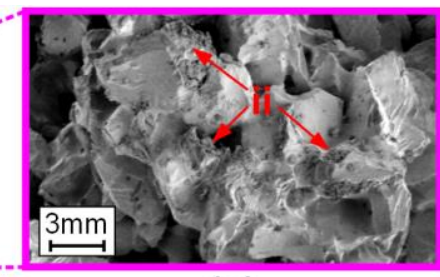

(c)

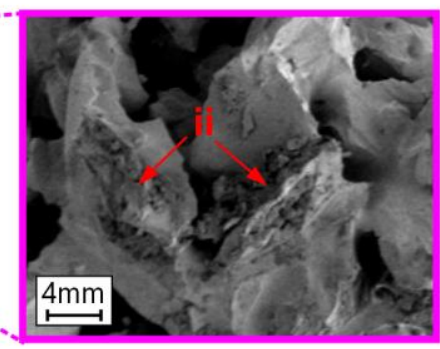

(d)

Figure 11. The SEM micrographs of the morphologies of the grinding wheel with PGA (a) before and (b) after the grinding trials with the removed workpiece volume of $20 \mathrm{~mm}^{3}$ (after 20 passes where $v_{s-2}$ is $25 \mathrm{~m} / \mathrm{s}, v_{w-2}$ is $2 \mathrm{~m} / \mathrm{min}$, and $a_{p-2}$ is $10 \mu \mathrm{m}$, i.e. $1 \mathrm{~mm}^{3}$ material removal per pass) where (c,d) limited volume of debris left on the grinding wheel surface due to the superior chip disposal ability of the PGA

As seen in Fig.11 (c) and (d), the debris of the workpiece material left on the grinding wheel surface can be another key observation. The left debris volume within the active-grinding 
region was limited (see ii in Fig.11c and d), which might probably due to the superior chip disposal ability of the PGA. The limited debris is expected to be able to help to avoid the wheel clogging and the corresponding consequences including poor ground surface texture, increased grinding forces and wheel wear.

\subsection{Comparison of the material removal efficiency between wheels with PGA and conventional wheels}

Except for wheel wear, the material removal efficiency is another key aspect to evaluate the inversely-designed wheels with PGA, and here two common assessment parameters (i.e. specific energy $e_{c}$ and G-ratio $G$ ) are employed as the indicators.

The specific energy $e_{c}$ refers to the required energy to remove per unit volume of workpiece material, and can be obtained by [2]:

$$
e_{c}=\frac{F_{t} \cdot v_{s}}{b \cdot a_{p} \cdot v_{w}}
$$

where $F_{t}$ refers to the tangential grinding force, which was captured by the dynamometer in the grinding trials, $v_{s}$ is the abrasive speed, $b$ is the wheel width, $a_{p}$ is the grinding depth, and $v_{w}$ is the workpiece feed speed.

Fig.12 (a) shows the specific energy comparison in both case 1 and 2. It can find that, $e_{c}$ for the wheel with PGA was $45 \mathrm{~J} / \mathrm{mm}^{3}$ in Case 1 and $9.45 \mathrm{~J} / \mathrm{mm}^{3}$ in Case 2, which was quite close to the value for the conventional wheel $\left(41.25 \mathrm{~J} / \mathrm{mm}^{3}\right.$ in Case 1 and $9.01 \mathrm{~J} / \mathrm{mm}^{3}$ in Case 2). This means the conventional wheel has higher material removal efficiency as it takes more energy for the wheel with PGA to remove the same volume of workpiece. However, this difference was slight and accounted for only $8.3 \%$ in percentage in Case 1 and $4.6 \%$ in Case 2. Considering the large temperature reduction (reduction of $61^{\circ} \mathrm{C}$ in Case 1 and $125^{\circ} \mathrm{C}$ in Case 2 as seen in Fig.9), the efficiency of the wheel with PGA can be considered acceptable.

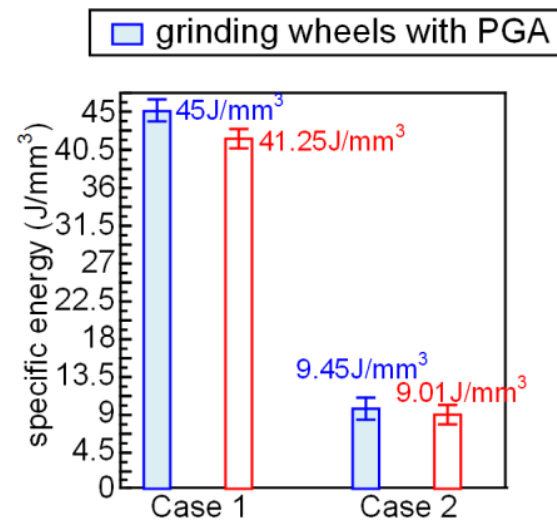

(a)

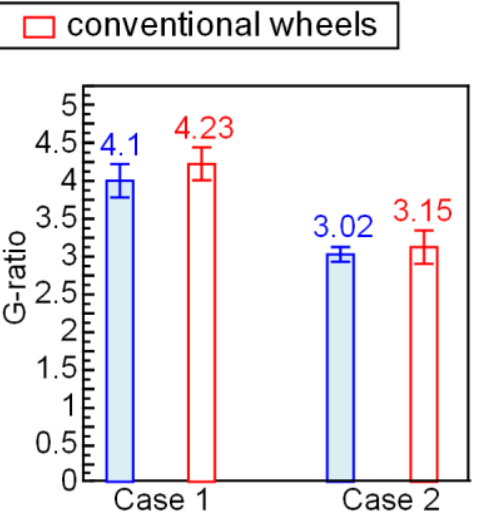

(b)

Figure 12. The material removal efficiency comparison between wheels with PGA and conventional wheels in terms of (a) specific energy, and (b) G-ratio 
Another assessment parameter G-ratio $G$ is defined as the volume of material removed divided by volume of wheel wear [2], i.e.

$$
G=\frac{V_{w}}{V_{s}}
$$

where the removed workpiece volume $V_{w}$ can be obtained by $V_{w} \approx b \cdot a_{p} \cdot l_{c}$, and the wheel wear volume $V_{s}$ can be achieved by $V_{s}=\pi \cdot b \cdot\left(r_{\text {before }}^{2}-r_{\text {after }}^{2}\right)$ with the measured wheel radius before and after the grinding trials $r_{\text {before }}$ and $r_{\text {after. }}$.

Fig.12 (b) gives the G-ratio comparison between the wheel with PGA and the conventional wheel in both Case 1 and 2, and the result was similar to the case for specific energy: the wheel with PGA showed slightly lower G-ratios in both Case 1 and 2, indicating the relatively weak ability of a grinding wheel to remove material. However, the difference was only $2.8 \%$ in Case 1 and $4.3 \%$ in Case 2. Therefore it would be reasonable to conclude that the material removal efficiency of the wheel with PGA can be acceptable.

\section{Conclusions}

We have developed a method which can inversely design the discontinuities, or the PGA, on the conventional abrasive tool surface based on the required tool performances (mainly based on grinding temperature, together with ground surface quality and grinding chatter). In the validation grinding trials performed by the tools with the designed PGA geometries, the grinding temperature, the ground surface roughness, and the grinding chatter have all satisfied the requirements, proving the method feasibility and accuracy. In comparison with the conventional tool, the inversely-designed tools have been found effective to reduce the harmful, or even destructive, thermal effects on the ground component surfaces in terms of the tool-workpiece contact zone temperature (the temperature were separately reduced by $61^{\circ} \mathrm{C}$ in Case 1 and $125^{\circ} \mathrm{C}$ in Case 2), the burn marks on the ground surface, and the heatinduced HAZs beneath the ground surface. Based on the inversely-calculated generic PGA geometry, two tools with the optimised PGA geometries have also been given to overcome some practical issues that can not be considered in the inverse method (e.g. the undesired axial grinding force). Although this paper has provided the fundamental studies on the inverse design of discontinuities on the tool surface, future work can be probably extended to the tools or the components with more complex shapes (for example, ball end, cup, or circular tools, and also free-form components). 


\section{References}

[1]. Goryacheva IG. 2013 Contact Mechanics in Tribology, Springer Netherlands.

[2]. Malkin S, Guo C. 2008 Grinding technology: Theory and application of machining with abrasives, McGraw-Hill.

[3]. Li HN, Axinte D. 2017 On a stochastically grain-discretised model for 2D/3D temperature mapping prediction in grinding. International Journal of Machine Tools and Manufacture 116, 60-76. (doi:10.1016/ j.jmachtools.2017.01.004)

[4]. Li HN, Axinte D. 2016 Textured grinding wheels: a review. International Journal of Machine Tools and Manufacture 109, 8-35. (doi:10.1016/j.jimachtools.2016.07.001)

[5]. Mohamed AMO, Bauer R, Warkentin A. 2013 Application of shallow circumferential grooved wheels to creep-feed grinding. Journal of Materials Processing Technology 213, 700-706. (doi:10.1016 /j.jmatprotec.2012.11.029)

[6]. Shi CF, Li X, Chen ZT. 2014 Design and experimental study of a micro-groove grinding wheel with spray cooling effect. Chinese Journal of Aeronautics 27, 407-412. (doi:10.1016/j.cja.2013.07.013)

[7]. Li X. 2014 Application of self-inhaling internal cooling wheel in vertical surface grinding. Chin. J. Mech. Eng. 27, 86-91. (doi:10.3901/CJME.2014.01.086)

[8]. Axinte D, Billingham J, Bilbao GA. 2017 New models for energy beam machining enable accurate generation of free forms. Science Advances 3. (doi:10.1126/sciadv.1701201)

[9]. Nguyen T, Zhang LC. 2006 The coolant penetration in grinding with a segmented wheel - Part 2: Quantitative analysis. International Journal of Machine Tools and Manufacture 46, 114-121. (doi:10.1016 /j.jijmachtools.2005.05.020)

[10]. Nguyen T, Zhang LC. 2005 The coolant penetration in grinding with segmented wheels -part 1: mechanism and comparison with conventional wheels. International Journal of Machine Tools and Manufacture 45, 1412-1420. (doi:10.1016/j.jmachtools.2005.01.035)

[11]. Sikorski KA. 2001 Optimal Solution of Nonlinear Equations, Oxford University Press.

[12]. Denkena B, Köhler J, Wang B. 2010 Manufacturing of functional riblet structures by profile grinding. CIRP Journal of Manufacturing Science and Technology 3, 14-26. (doi:10.1016/j.cirpj.2010.08.001)

[13]. Denkena B, Grove T, Göttsching T, da SE, Coelho R, Filleti R. 2015 Enhanced grinding performance by means of patterned grinding wheels. Int J Adv Manuf Technol 77, 1935-1941. (doi:10.1007/s00170-0146579-8)

[14]. Denkena B, Grove T, Göttsching T. 2015 Grinding with patterned grinding wheels. CIRP Journal of Manufacturing Science and Technology 8, 12-21. (doi:10.1016/j.cirpj.2014.10.005)

[15]. Li HN, Yu TB, Zhu LD, Wang WS. 2015 Analysis of loads on grinding wheel binder in grinding process: insights from discontinuum-hypothesis-based grinding simulation. Int J Adv Manuf Technol 78, 19431960. (doi:10.1007/s00170-014-6767-6)

[16]. Li HN, Yu TB, Zhu LD, Wang WS. 2015 Modeling and simulation of grinding wheel by discrete element method and experimental validation. Int J Adv Manuf Technol 81, 1921-1938. (doi:10.1007/s00170-0157205-0)

[17]. Nguyen N, Ohta A, Matsuoka K, Suzuki N, Maeda Y. 1999 Analytical solutions for transient temperature of semi-infinite body subjected to 3-D moving heat sources. Welding Research 78, 265-274. 
[18]. Chen W, d KFD, Kaloni PN. 2003 Advanced Mathematics for Engineering and Science, World Scientific.

[19]. Michael JM, Howard NS, Bruce RM, David PD. 2003 Introduction to Thermal Systems Engineering: Thermodynamics, Fluid Mechanics, and Heat Transfer, John Wiley \& Sons.

[20]. Davis PJ, Rabinowitz P, Rheinbolt W. 2014 Methods of Numerical Integration, Elsevier Science.

[21]. Kuffa M, Kuster F, Wegener K. 2017 Comparison of lubrication conditions for grinding of mild steel with electroplated cBN wheel. CIRP Journal of Manufacturing Science and Technology 18, 53-59. (doi:10.1016/j.cirpj.2016.09.002)

[22]. Yao CF, Wang T, Xiao W, Huang XC, Ren JX. 2014 Experimental study on grinding force and grinding temperature of Aermet 100 steel in surface grinding. Journal of Materials Processing Technology 214, 2191-2199. (doi:10.1016/j.jmatprotec.2014.04.013) 